\title{
Surface Geophysical Exploration of TX-TY Tank Farms at the Hanford Site: Results of Background Characterization with Ground Penetrating Radar
}

Prepared by B. Cubbage, R. Brauchla, G. O'Brien, M. Bergeron, hydroGEOPHYSICS. Inc. and C. Henderson, Columbia Energy \& Environmental Services, Inc. for CH2M HILL Hanford Group, Inc.

Richland, WA 99354

U.S. Department of Energy Contract DE-AC27-99RL14047

$\begin{array}{lll}\text { EDT/ECN: } & \text { DRF } & \text { UC: } \\ \text { Cost Center: } & & \text { Charge Code: } \\ \text { B\&R Code: } & & \text { Total Pages: } 39\end{array}$

Key Words: Ground-Penetrating Radar, TX Tank Farm, TY Tank Farm, Surface Geophysical Exploration

Abstract: Ground penetrating radar surveys of the TX and TY tank farms were performed to identify existing infrastructure in the near surface environment. These surveys were designed to provide background information supporting Surface-to-Surface and Well-to-Well resistivity surveys of Waste Management Area TX-TY.

TRADEMARK DISCLAIMER. Reference herein to any specific commercial product, process, or service by trade name, trademark, manufacturer, or otherwise, does not necessarily constitute or imply its endorsement, recommendation, or favoring by the United States Government or any agency thereof or its contractors or subcontractors.

Printed in the United States of America. To obtain coples of this document, contact: Document Control Services, P.O. Box 950, Mailstop H6-08, Richland WA 99352, Phone (509) 372-2420; Fax (509) 376-4980

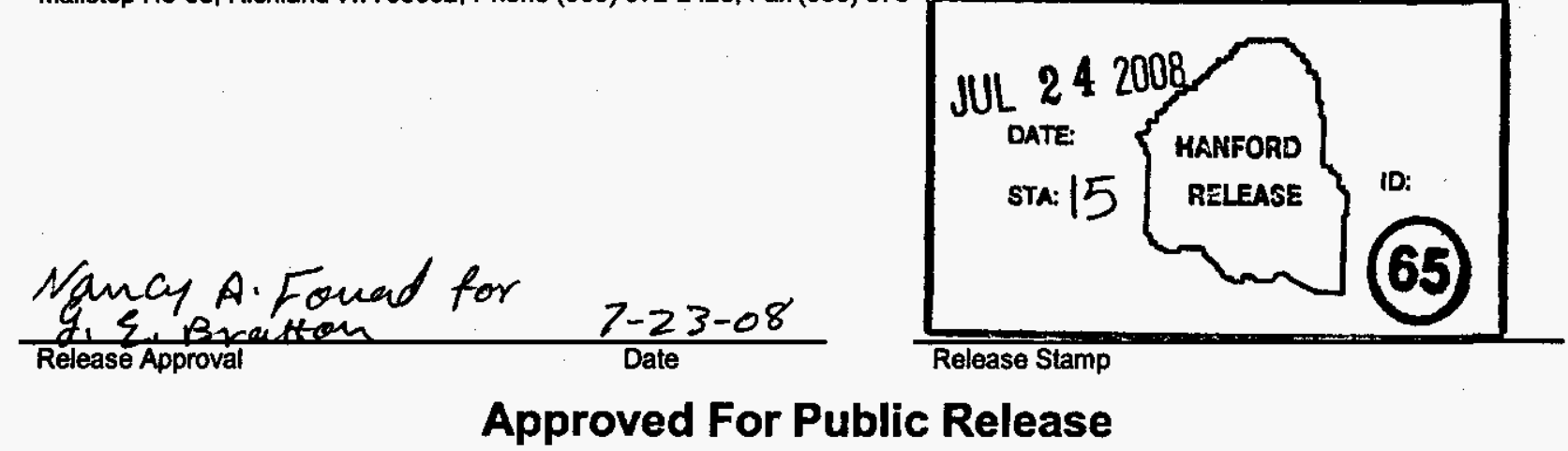


RPP-RPT-38104, Rev. 0

\section{EXECUTIVE SUMMARY}

This report documents the results of ground penetrating radar survey as part of the surface geophysical exploration (SGE) activities performed between March and April 2008 at the TX and TY tank farms. The TX-TY tank farm area is located in the 200 West Area of the U.S. Department of Energy Hanford Site in Washington State. The objective of the preliminary investigation was to collect background characterization information with GPR to understand the spatial distribution of metallic objects that could potentially interfere with the results from high resolution resistivity ${ }^{\mathrm{TM}}$ surveys.

The results of the background characterization confirm the existence of documented infrastructure, as well as highlight locations of possible additional undocumented subsurface metallic objects.

Figures ES-1 and ES-2 show the results of the interpreted pipe infrastructure within the north and south parts of TX tank farm. With the frequency of the GPR at 250 megahertz, pipes within 10 feet of the surface could be imaged effectively. The depth of investigation depends on the loessy nature of the soil, which is controlled by mineral and water content.

The use of a real time kinematic survey grade global positioning system on this survey improved the survey accuracy from sub-meter in previous SGE surveys to sub-centimeter.

It is recommended that if deeper surveying is needed then a lower frequency ground penetrating radar antenna be utilized. However, a lower frequency antenna has a larger minimum target size for detection.

\footnotetext{
${ }^{\mathrm{rM}}$ High resolution resistivity is a trademark of hydroGEOPHYSICS, Inc.
} 
Figure ES-1. Interpreted Locations and Depths of Pipe Infrastructure in 241-TX-Farm.

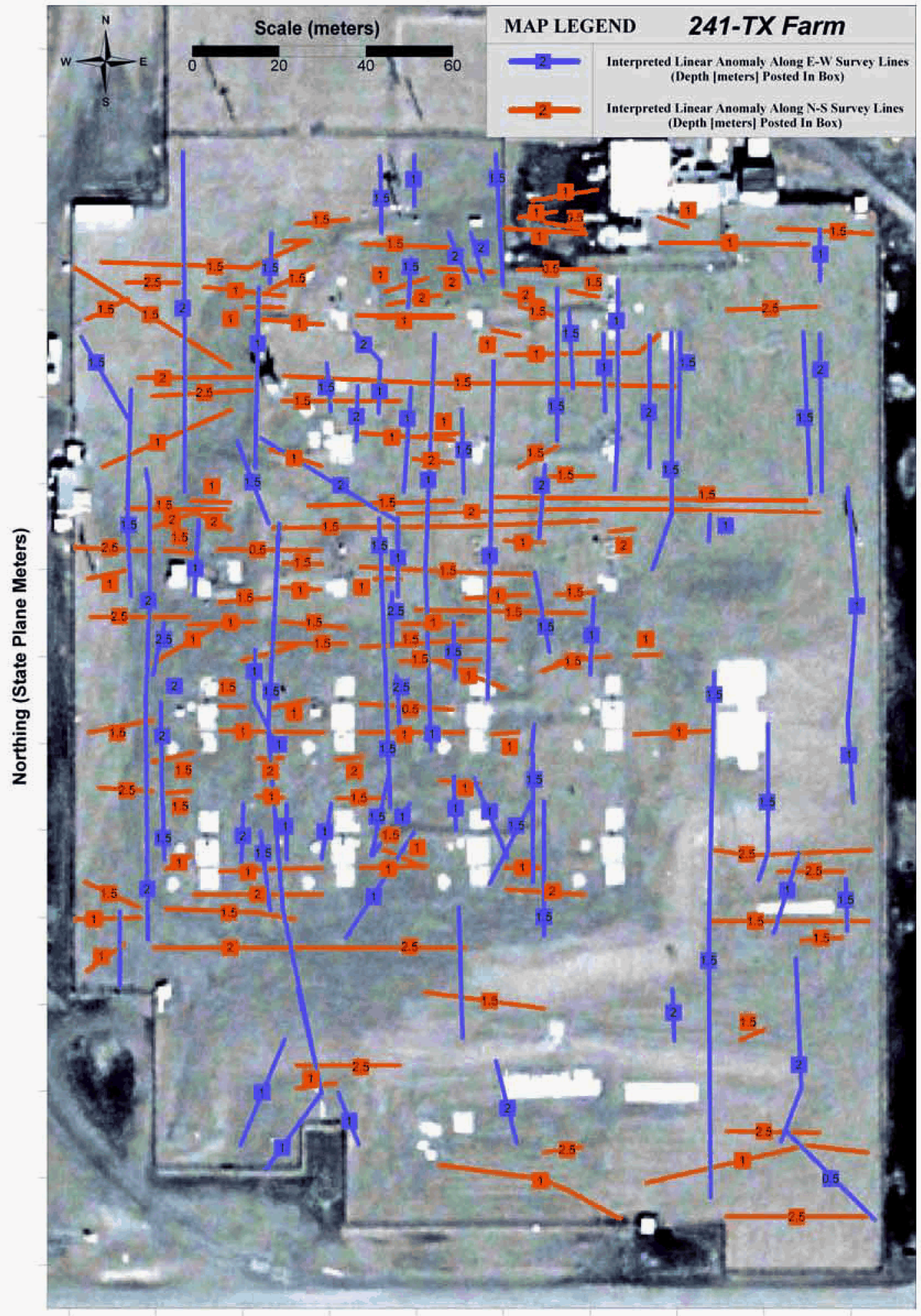

Easting (State Plane Meters) 
Figure ES-2. Interpreted Locations and Depths of Pipe Infrastructure in 241-TY-Farm.

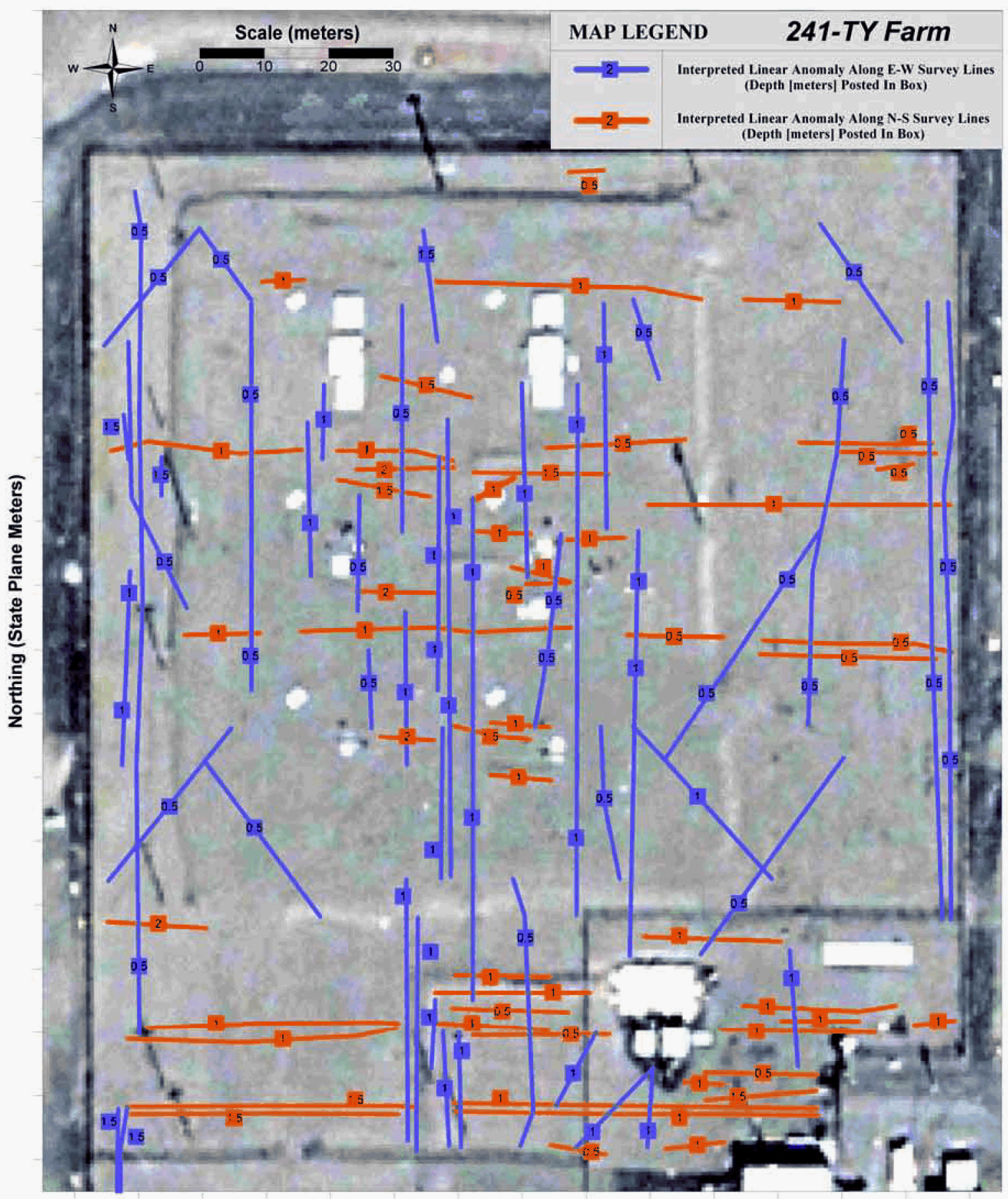

Easting (State Plane Meters) 


\section{TABLE OF CONTENTS}

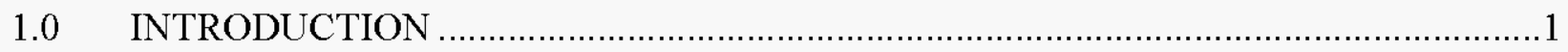

$1.1 \quad$ SCOPE

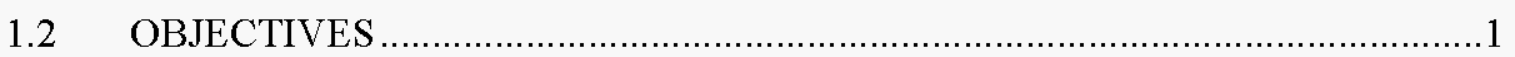

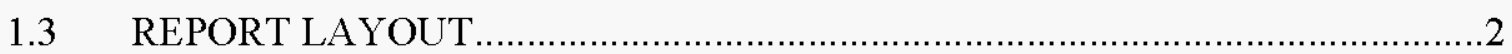

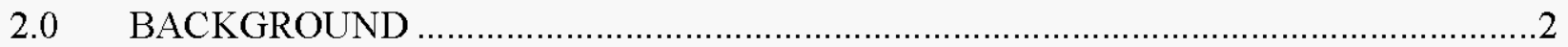

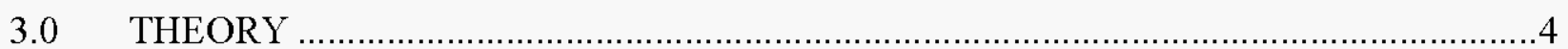

3.1 GROUND PENETRATING RADAR ..........................................................

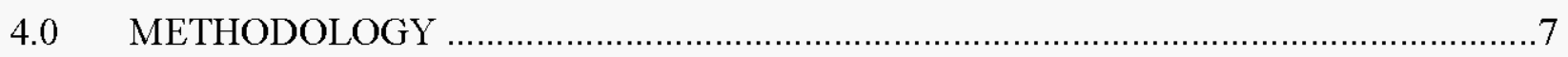

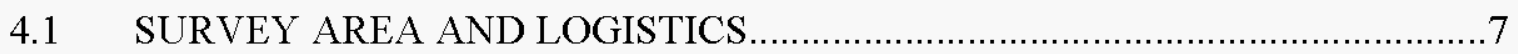

4.2 GEOPHYSICAL AND NAVIGATIONAL EQUIPMENT ………....................10

4.2.1 Noggin 250 Ground Penetrating Radar System and Smart Cart...............10

4.2.2 Leica 1200 RTK Global Positioning System..........................................10

4.2.3 Ag Leader Technology Heads-Up Display/GPS Lightbar........................10

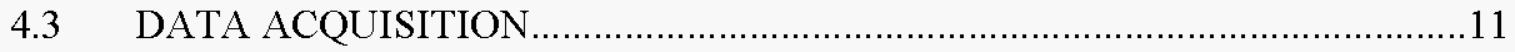

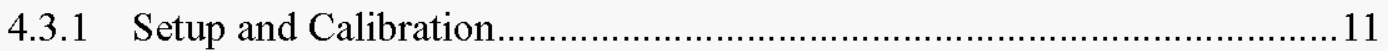

4.3.2 Field Notation and Data Organization .................................................11

4.3.3 Data Collection ........................................................................... 12

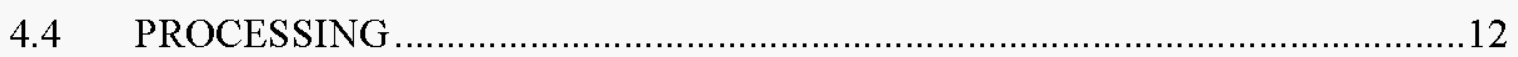

4.4.1 Downloading, Parsing, Quality Control - Onsite …….............................12

4.4.2 Processing and Plotting ..................................................................... 13

5.0 ANALYSIS, RESULTS AND INTERPRETATION

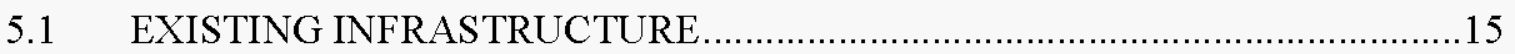

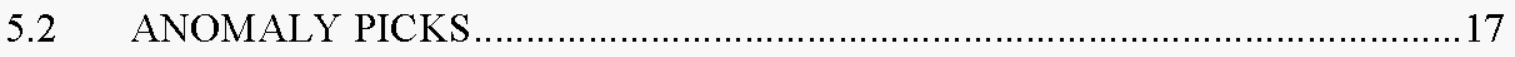

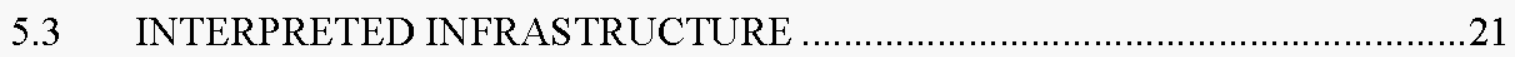

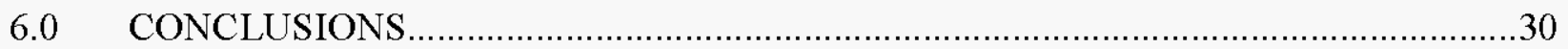

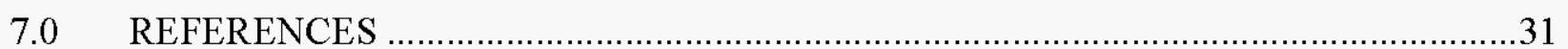




\section{LIST OF FIGURES}

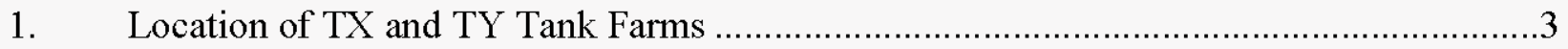

2. TX-TY Tank Farms and Surrounding Facilities and Wells ........................................

3. GPR Coverage - TX and TY Tank Farm Areas that Include the Alpha-zone,

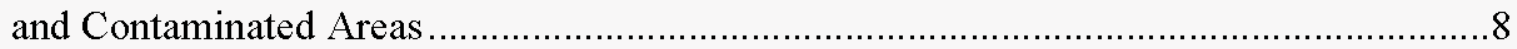

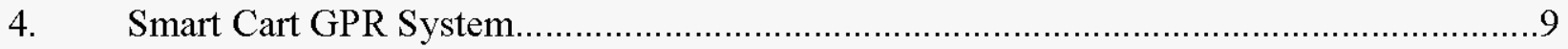

5. Ag Leader Technology Heads-Up Display .................................................................... 11

6. Example Interpretation of GPR Hyperbola Picks ................................................ 14

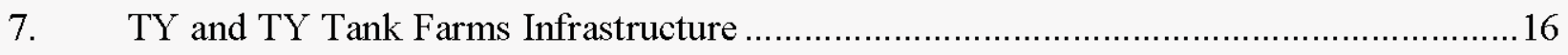

8. East-West Anomaly Picks in 241-TX Farm ........................................................ 18

9. North-South Anomaly Picks in 241-TX Farm ............................................................... 19

10. East-West Anomaly Picks in 241-TY Farm ...........................................................20

11. North-South Anomaly Picks in 241-TY Farm .........................................................21

12. Interpreted Infrastructure in 241-TX Tank Farm (North Area) ..................................22

13. Interpreted Infrastructure in 241-TX Tank Farm (South Area) ...................................23

14. Interpreted Infrastructure in 241-TY Tank Farm (North Area) ..................................24

15. Interpreted Infrastructure in 241-TY Tank Farm (South Area) ...................................25

16. Interpreted Locations and Depths of Pipe Infrastructure in 241-TX Farm

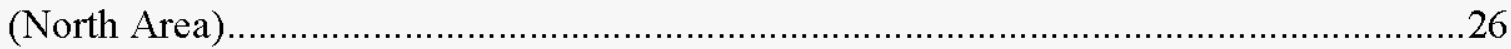

17. Interpreted Locations and Depths of Pipe Infrastructure in 241-TX Farm

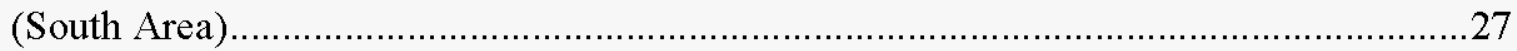

18. Interpreted Locations and Depths of Pipe Infrastructure in 241-TY Farm

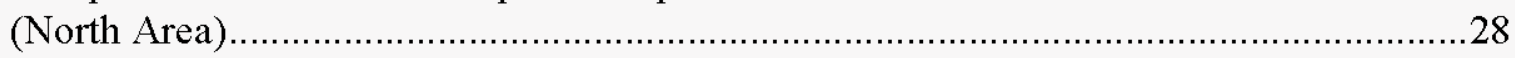

19. Interpreted Locations and Depths of Pipe Infrastructure in 241-TY Farm (South Area)...

\section{LIST OF TABLES}

1. Survey Dates, Locations Surveyed, File Folder Paths of Stored Data, and Number of Lines Collected for Each Data Set in TX-TY Farm GPR Survey. 
RPP-RPT-38104, Rev. 0

\section{LIST OF TERMS}

$\begin{array}{ll}\text { CA } & \text { contamination area } \\ \text { CH2M HILL } & \text { CH2M HILL Hanford Group, Inc. } \\ \text { DVL } & \text { digital video logger } \\ \text { GPR } & \text { ground penetrating radar } \\ \text { GPS } & \text { Global Positioning System } \\ \text { HGI } & \text { hydroGEOPHYSICS, Inc. } \\ \text { HRRTM } & \text { high resolution resistivity } \\ \text { RTK } & \text { real time kinematic } \\ \text { SGE } & \text { surface geophysical exploration } \\ \text { SST } & \text { single-shell tank }\end{array}$

\section{LIST OF TRADEMARKS}

Leica

Registered trademark of Leica Geosystems, AG.

High resolution Trademark of hydroGEOPHYSICS, Inc. resistivity (HRR)

Noggin

Registered trademark of Sensors \& Software, Inc.

Surfer

Registered trademark of Golden Software, Inc. 


\subsection{INTRODUCTION}

Beginning in September 2007 and ending in March 2008, a preliminary geophysical study was completed within the 241-TX and 241-TY tank farm area at the U.S. Department of Energy Hanford Site in eastern Washington State. hydroGEOPHYSICS, Inc. (HGI) of Tucson, Arizona and Columbia Energy \& Environmental Services, Inc. of Richland, Washington, and, with support from CH2M HILL Hanford Group, Inc. (CH2M HILL) conducted background geophysical surveys of the TX-TY tank farm area located in the 200 East Area of the Hanford Site. The geophysical surveys consisted of ground penetrating radar (GPR) within the boundaries of the TX and TY tank farms.

\subsection{SCOPE}

The scope of the geophysical surveying included data acquisition, processing, and visualization of GPR data collected within the boundaries of the TX-TY tank farms. The GPR survey was performed in accordance with RPP-PLAN-35244, Work Plan for Surface Geophysical Exploration of the TX and TY Tank Farm and Surrounding Area. The data consisted of an amplitude value of the received electric field. The amplitude was discriminated for targets consisting of buried infrastructure.

Data acquisition was conducted using a Noggin ${ }^{\circledR} 250$ Smart Cart system, which included a GPR system (transmitting and receiving antennae, battery, and energy source) and digital output display, both housed on a fiberglass cart. The Smart Cart was outfitted with a Leica ${ }^{\circledR} 1200$ RTK global positioning system (GPS) unit for geo-referencing of data and an Ag Leader Technology Heads-Up Display/GPS Lightbar to allow real-time navigation while traversing the area. Data coverage included a total of 30.42 line-kilometers throughout the tank farms. Total aerial coverage of the GPR survey was approximately 15.95 acres.

\subsection{OBJECTIVES}

The main objective for this geophysical investigation was to map the subsurface with regards to the extent of infrastructure and debris. Much of the subsurface infrastructure is metallic and may interfere with electrical resistivity measurements, which had already been conducted in the second phase of the surface geophysical exploration (SGE) scope for the TX-TY tank farm geophysical characterization. The results of ex-farm mapping with electromagnetic induction and magnetic gradiometry outside of the tank farm boundaries were presented in a previous report (Surface Geophysical Exploration of TX and TY Tank Farms at the Hanford Site: Results of Background Characterization with Magnetics and Electromagnetics [RPP-RPT-36893]). The results of the electrical resistivity characterization survey will be presented in a subsequent report. 


\subsection{REPORT LAYOUT}

This report is divided into seven main sections.

Section 1.0, Introduction - Describes the scope and objectives of the investigation.

Section 2.0, Background - Describes the setting of the TX and TY tank farm area and information regarding the metallic infrastructure in and around the tank farm.

Section 3.0, Theory - Discusses some of the theory behind ground penetrating radar.

Section 4.0, Methodology - Discusses the methodology and logistics of conducting the geophysical survey at the TX-TY tank farm area.

Section 5.0, Analysis, Results and Interpretation - Presents the results from the surveying effort.

Section 6.0, Conclusions - Provides conclusions drawn from the results, interpretations, and subsequent assessment of results.

Section 7.0, References - Lists reference documents cited in the report.

\subsection{BACKGROUND}

The TX and TY tank farms comprise waste management area TX-TY. These tank farms are located in the northern portion of the 200 West Area, southwest and west of T Plant (Figure 1). 
Figure 1. Location of TX and TY Tank Farms.

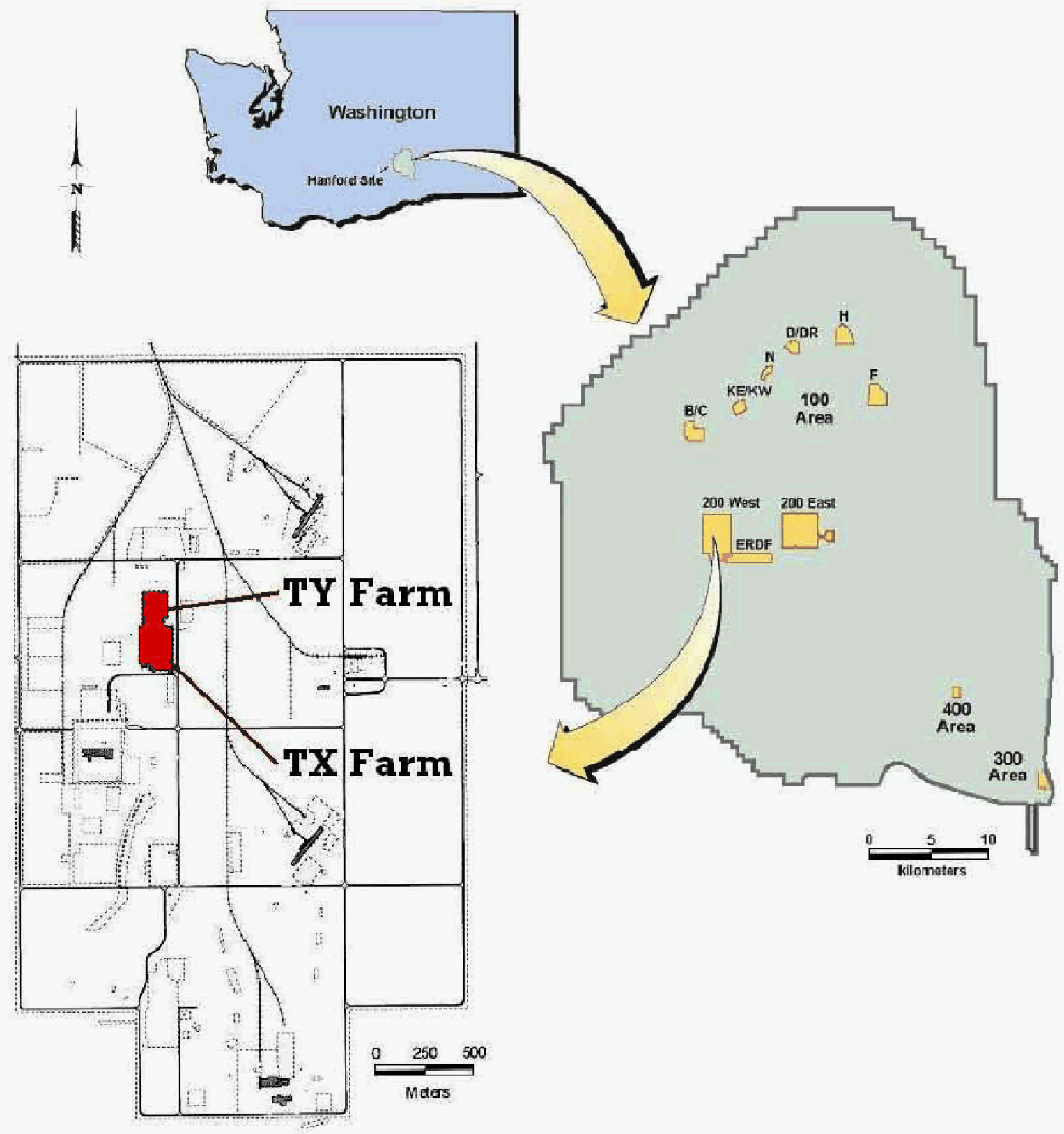

The TX tank farm comprises the following:

18 single-shell tanks (SSTs) each with 2,006,050-liter (758,000-gallon) capacity Waste transfer lines Leak detection systems Tank ancillary equipment. 
The TY tank farm comprises the following:

6 SSTs each with 2,006,050-liter (758,000-gallon) capacity

Waste transfer lines

Leak detection systems

Tank ancillary equipment.

The SSTs in these tank farms are 23 meters ( 75 feet) in diameter and approximately 11.4 meters (37.25 feet) tall from the base to the apex of the dome. The sediment cover from the apex of the dome to ground surface is 2.5 meters ( 8.1 feet) at the TX and TY tank farms. All of the tanks have a dish-shaped bottom. Eight of the 18 SSTs in TX tank farm and five of the six SSTs in TY tank farm are classified as assumed leakers (Waste Tank Summary Report for Month Ending November 30, 2004 [Hanlon 2005]). The SSTs in TX Farm were constructed with cascade overflow lines in a pair of three-tank series and three four-tank series that allowed gravity flow of liquid waste between the tanks. The SSTs in TY Farm were also constructed with a pair of three-tank cascade overflow lines (Historical Tank Content Estimate for the Northwest Quadrant of the Hanford 200 West Area [Brevick 1995]). Figure 2 shows the details of the TX-TY tank farm area with assumed leaking tank locations, wells, and other facilities.

The area around the 244-TX double-contained receiver tank is designated as an alpha zone due to the potential fore near-surface alpha contamination. The area just south of the $242-\mathrm{T}$ evaporator is designated as a contaminated area. Additional access requirements (personal protective equipment and surveys) were required to perform GPR surveys of these areas.

\subsection{THEORY}

This chapter provides a summary level description for the theory behind the geophysical tools and methods used in the assessment.

\subsection{GROUND PENETRATING RADAR}

Ground penetrating radar uses electromagnetic fields to probe loessy dielectric materials to detect structures and changes in material properties within the materials ("Ground penetrating radar for high resolution mapping of soil and rock stratigraphy" [Davis and Annan, 1989]).

Ground penetrating radar is a non-destructive subsurface imaging technique where short radar pulses, in the range of 1 to 1,000 megahertz, are emitted into the ground. The velocity of these waves is controlled by the dielectric constant (relative permittivity) of a material and therefore varies with physical property changes in the subsurface. A reflection signal, from which subsurface anomalies can be observed, is received and logged by the GPR system.

Depth of penetration depends both on the frequency of the radar waves and the permittivity of the material through which they travel. Both water content and porosity are defining factors in determining investigation depth. Generally, depth of penetration of a radar pulse increases with 
increasing resistivity. Previous experience with a 250-megahertz antenna within the Hanford tank farm environment has produced investigation depths of up to 3 meters (10 feet).

The GPR system is housed within a fiber-glass cart, permitting rapid, non-contact surveys.

Ground penetrating radar was used inside the tank farms to locate buried metallic objects and features. Portable (one person) field units can be used virtually anywhere that the cart can traverse. 
Figure 2. TX-TY Tank Farms and Surrounding Facilities and Wells.*

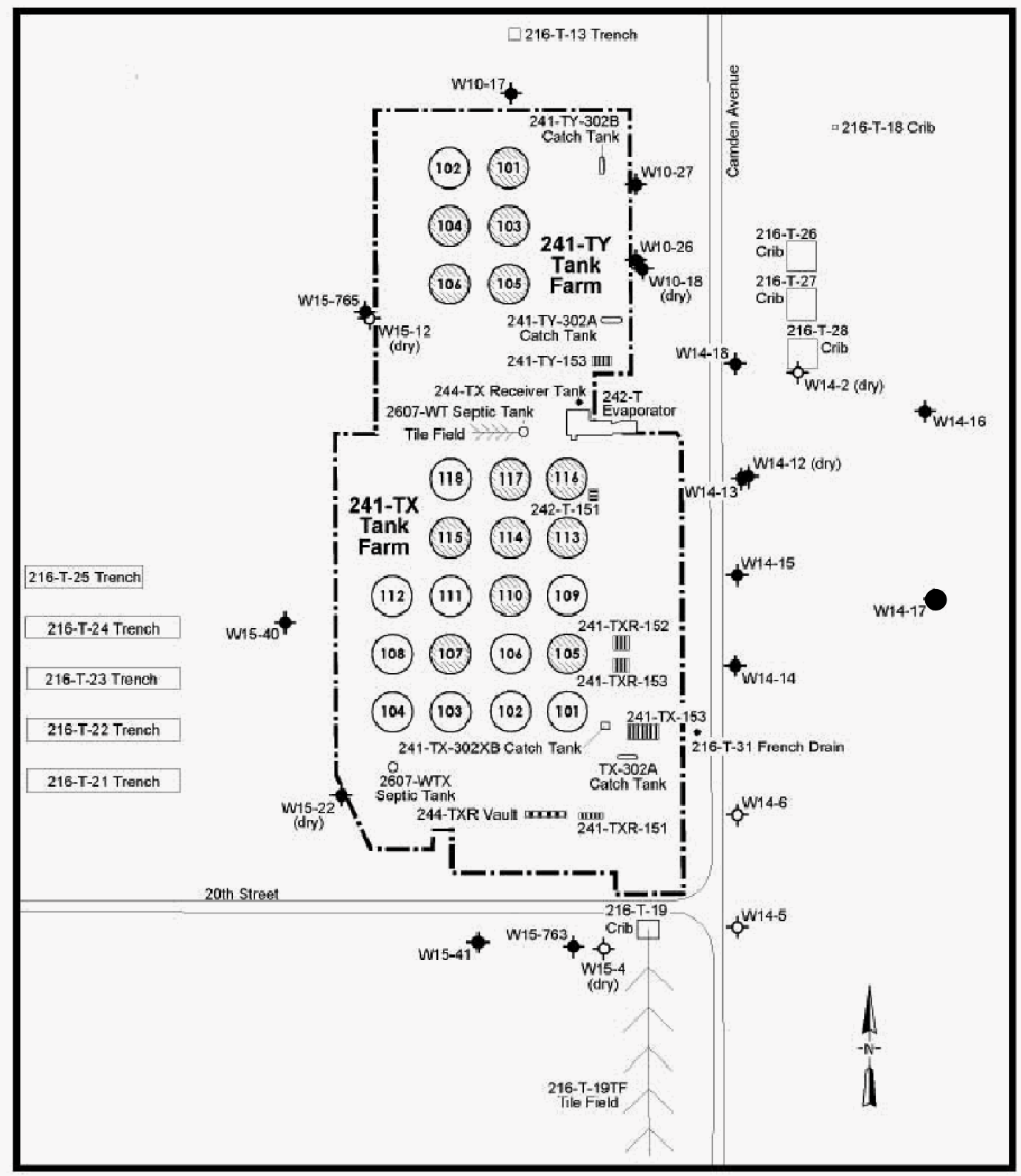

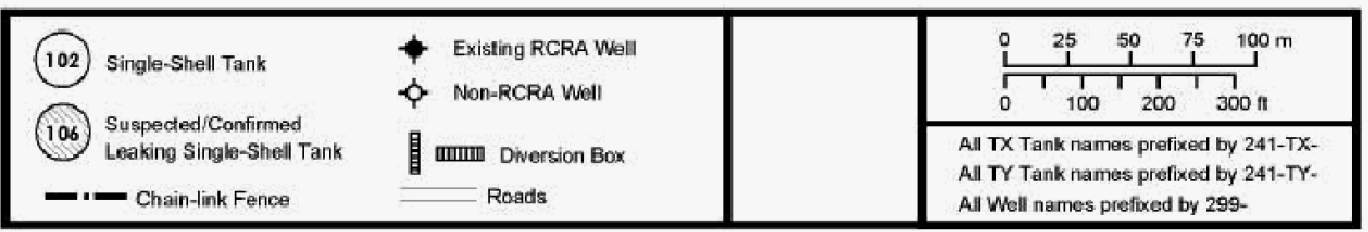

*Mo dified from Reidel, S.P., D.G. Horton, Y.J. Chien, D.B. Barnett, and K. Singleton, 2006, Gaology, Hydrogeology, Geochemisty, and Mnernlogy Data Package for the Single-Shell Tank Wante Management Aneas at the Hanford Site, RPP- 23748, Revision 0, CH2M HILL Hanford Group, Inc., Richland, Washington. 


\subsection{METHODOLOGY}

\subsection{SURVEY AREA AND LOGISTICS}

This section describes the equipment and methodology used to collect, manage, and process geophysical data from within TX and TY tank farms. A summary of the survey coverage area for TX and TY tank farms can be viewed in Figure 3, which was created by plotting the GPS data file, with one point for each GPS data point recorded by the GPR data logger. Gaps in survey coverage were due to surface obstacles including fences, power poles, barriers around breather filters which prevented the operators of the Smart Cart from gaining access to these areas, and concrete and foam pads and covers which prevent satisfactory data collection.

Initial testing of the data collection system commenced on March 13, 2008, using the Noggin 250 Smart Cart GPR system. The Smart Cart (Figure 4) was equipped with a pair of antennae, battery, and power console, a digital video logger (DVL) for real-time display during data acquisition, a Leica 1200 real time kinematic (RTK) GPS for geo-referencing of geophysical data, and an Ag Leader Technology Heads-Up Display/GPS Lightbar for real-time navigation over a virtual grid. Testing included configuring the three systems to operate simultaneously, training of personnel responsible for collecting data within the tank farm boundary, and ensuring that the data acquisition parameters were sufficient for the survey. The GPS and heads-up navigation system allowed the operators to dispense with time consuming survey layout (tape measure and reference stakes), instead relying on a preprogrammed line layout within the GPS to guide the surveying. 
Figure 3. GPR Coverage - TX and TY Tank Farm Areas that Include the Alpha-zone, and Contaminated Areas.

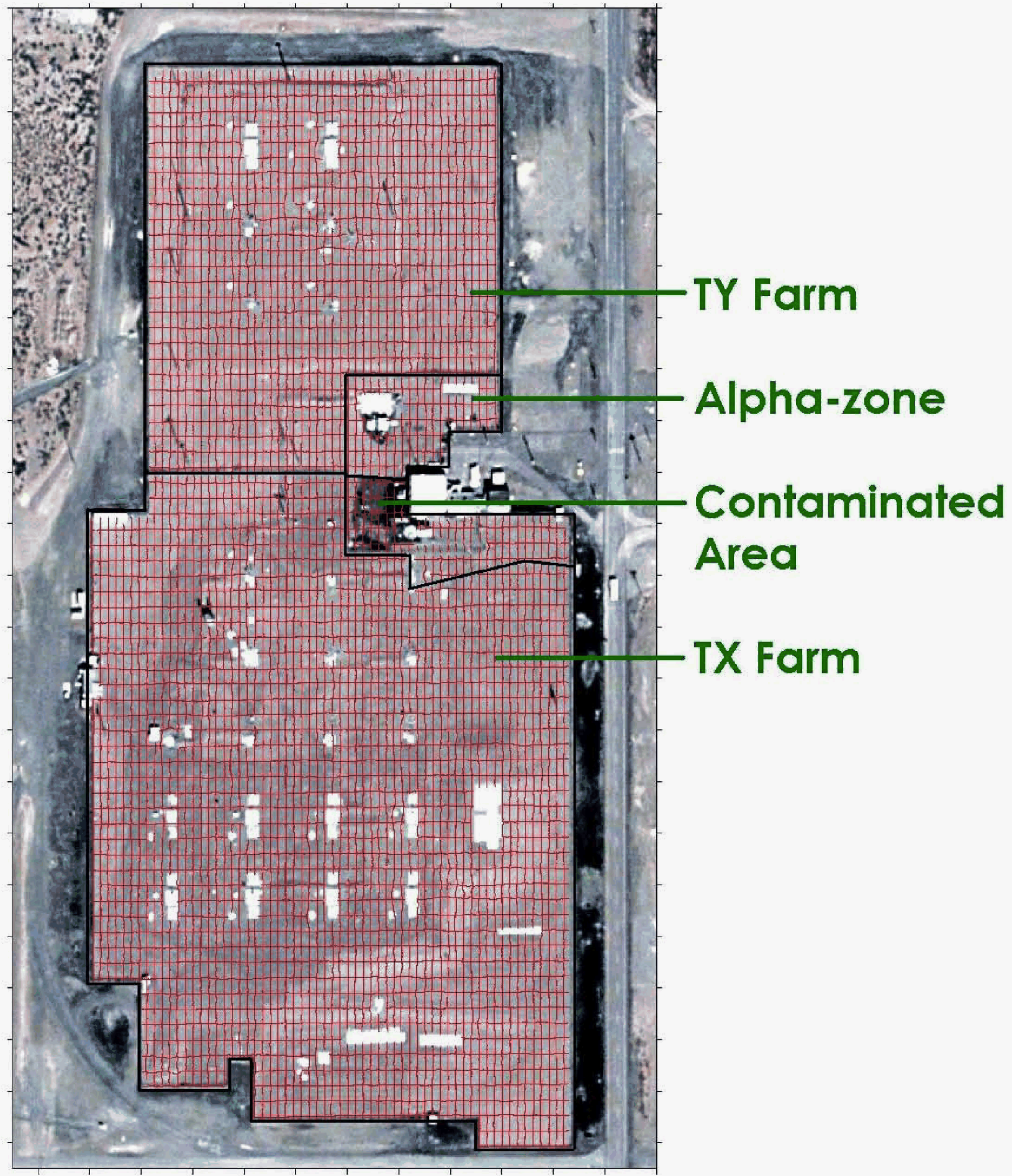


Figure 4. Smart Cart GPR System.

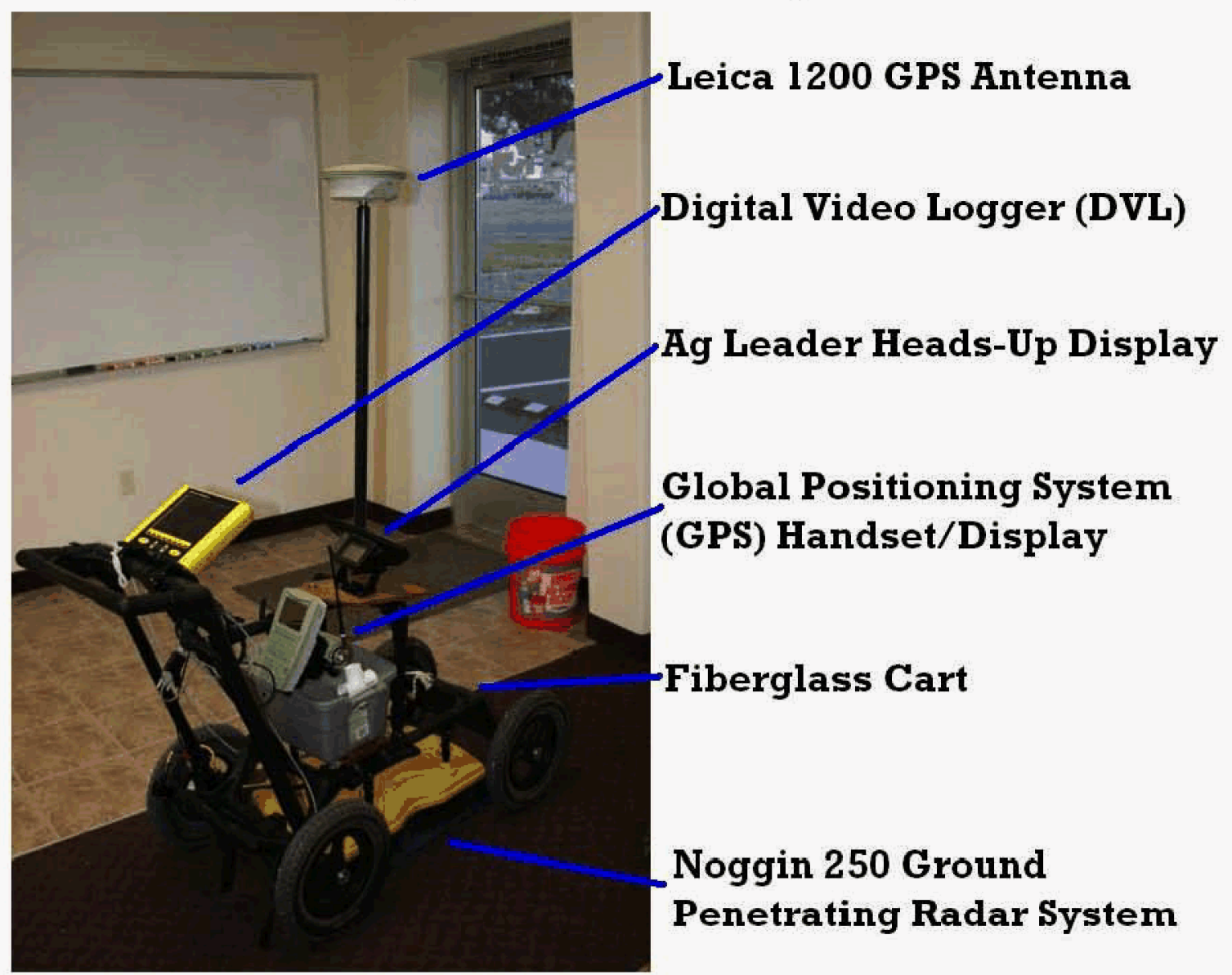




\subsection{GEOPHYSICAL AND NAVIGATIONAL EQUIPMENT}

GPR and GPS data were collected on a virtual grid in TX and TY Farms. The geophysical instruments used to collect data, as well as the equipment used to navigate the virtual grid, are described in the following sections.

\subsubsection{Noggin 250 Ground Penetrating Radar System and Smart Cart}

The Smart Cart is comprised of a fiber-glass cart that houses an odometer built in to the rear left wheel, a 250 megahertz GPR antenna, a DVL for viewing real-time subsurface images in scrollmode, and a rechargeable lithium-ion battery. The GPR data were recorded twenty times per meter (five centimeter trace) based on the odometer. GPR data were collected in "Line" mode and monitored during collection using the DVL. Data for each "line" is saved in the memory card on the DVL in the form of .HD and .DT1 files. .HD corresponds to GPR header information, and DT1 is the actual binary GPR data containing amplitude values for each trace.

\subsubsection{Leica 1200 RTK Global Positioning System}

A Leica 1200 RTK GPS was used to establish the physical location of the GPR data. The Leica base station antenna was set up at a known point southeast of the survey area from which radio communication between base station and rover was established. The rover antenna was attached to the GPR Smart Cart along with the handset display. The GPS was activated and inspected to ensure suitable accuracy and continuous communication between the GPR and GPS equipment.

All data were collected in RTK Mode, ensuring an accuracy of better than three centimeters. Data were recorded in the configuration of a National Marine Electronics Association string. Data for each "line" were saved in the memory card of the DVL in the form of a .GPS file which contains positional data for every fifth trace.

\subsubsection{Ag Leader Technology Heads-Up Display/GPS Lightbar}

An Ag Leader Technology Heads-Up Display/GPS Lightbar was connected to the GPS in order to aid in navigation by projecting a virtual grid onto the survey area. This grid consisted of "swaths" parallel to known zero lines (i.e., lines of origin along the southernmost and westernmost fence-lines of TX Farm). East-west swaths were set at a spacing of 6 meters (10 feet) and north-south lines were set at a spacing of 3 meters (10 feet). The line spacing was designed to be suitable for supporting the SGE resistivity survey and not for site clearance purposes. The navigational display is set to alert the Smart Cart operator if accuracy is lost due to the operator steering more than 24 centimeters ( 9.5 inches) off the swath or RTK mode being lost by the Leica (Figure 5). 
Figure 5. Ag Leader Technology Heads-Up Display.*

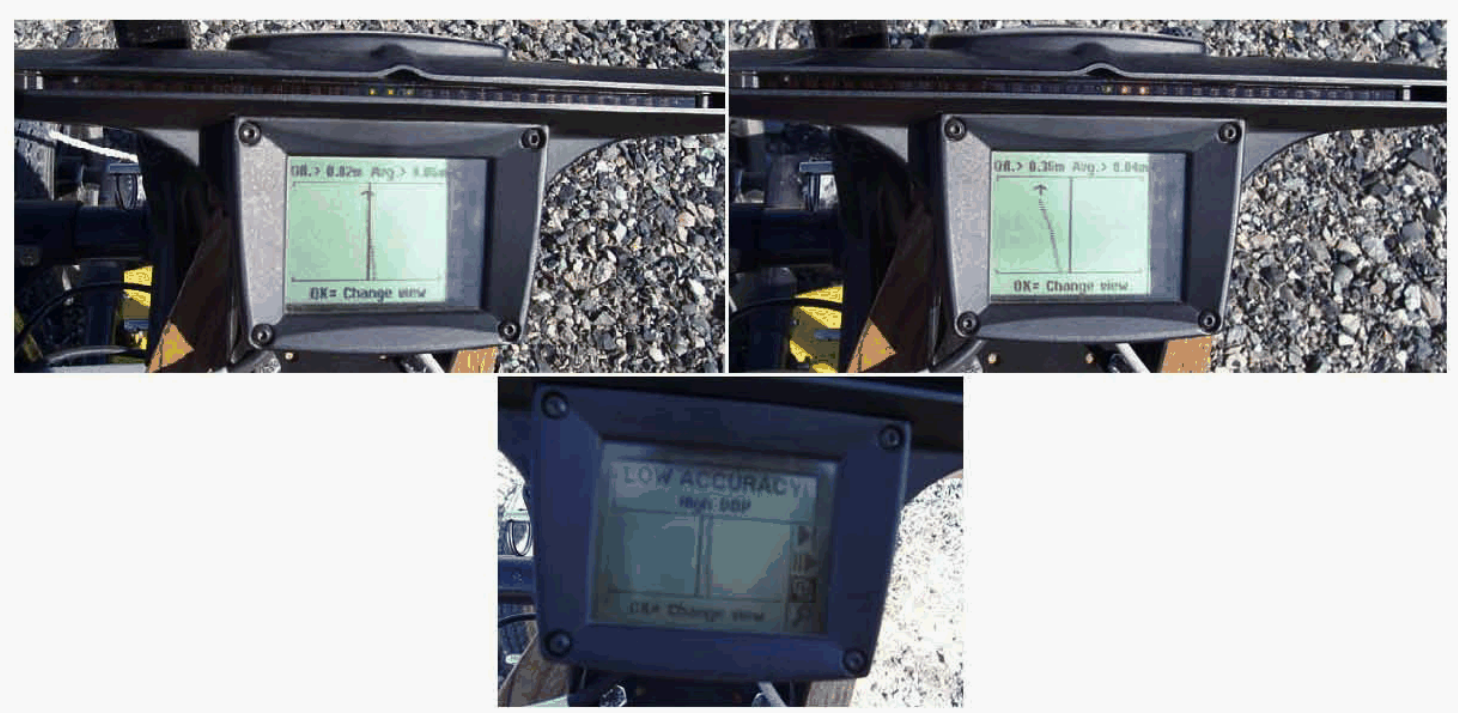

${ }^{*}$ Clockwise from Upper Left: On-course Display, Off-course Display, Loss of RTK Display.

\subsection{DATA ACQUISITION}

\subsubsection{Setup and Calibration}

Prior to surveying each day, GPR equipment was calibrated for site conditions. The GPS base station antenna was set up at a known point southeast of the survey area and radio communication between base station and rover was established. The GPS rover and navigational display were activated and inspected to ensure suitable accuracy and continuous communication between the GPR and GPS equipment.

The GPR was set to record one trace, equivalent to a data point, every five centimeters. The GPS was programmed to append positional (northing, easting, elevation) information to the GPR data record, recording one GPS data point for every five GPR traces, and saving one set of data files to the DVL for each line. The Ag Leader navigational display was calibrated against the southernmost fence line for east-west swaths (westernmost for north-south swaths) and programmed to space the swaths at intervals of six meters for east-west swaths or three meters for north-south swaths.

\subsubsection{Field Notation and Data Organization}

At the beginning of each day, a new project folder was opened in the memory of the DVL. Lines of data were collected in these folders, each of which represented a section of a swath between two obstacles, two tank farm boundaries, or an obstacle and a tank farm boundary. The Smart Cart operator would note the project, swath, direction, and bracketing boundaries or obstacles for 
each line. These would all be recorded, along with the setup and calibration parameters, on the project field form.

\subsubsection{Data Collection}

GPR lines were collected by a primary operator who pushed the Smart Cart along one of the swaths of the virtual grid according to the navigational display. A secondary operator would also remain on hand to help navigate the Smart Cart over difficult terrain. When an obstacle blocked the way, the operator would stop collection, navigate around the obstacle, realign the Smart Cart with the swath according to the GPS lightbar navigation, and begin collecting a new line of data.

GPR swaths were collected in a generally bi-directional pattern where operators collected one swath from west to east and then the subsequent swath from east to west. In most cases, however, the fences between TX and TY farms and around the alpha-radiation zone and Contamination Area (CA) made a purely bi-directional pattern unfeasible. Therefore, east-west lines were collected first in the TX tank farm area, then in TY tank farm area, then in the alphazone area. This process was then repeated in the north-south direction. The CA was surveyed last and all in the same day in order to decrease the risk of contamination that comes with multiple trips into these areas. The data, recorded in the DVL's memory in .HD, .DT1, and .GPS formats, were then uploaded to a computer in the field for preliminary processing and eventual upload to the HGI server.

\subsection{PROCESSING}

\subsubsection{Downloading, Parsing, Quality Control - Onsite}

GPR data were collected inside the TX and TY tank farm perimeters, and were not collected outside the tank farm fences. Table 1 lists selected information for the TX-TY farm GPR survey that include information on the survey date, the locations surveyed, and file folder paths where data for each day of the survey is stored, as well as the number of lines collected for each data set. Data files within each folder with the file name ending in .GPS correspond to GPS data. Data files within each folder with a file name ending in .HD corresponds to GPR header information. Data files within each folder with a file name ending in .DT1 include the actual binary GPR data containing amplitude values for each trace. A trace, collected every 5 centimeters (1.9 inches), consists of 311 digitized amplitude values, (electric field values in millivolts).

To assist with on-site data acquisition quality control, operators plotted and reviewed the GPS locations on the TX/TY tank farm map on a daily basis during the survey. This procedure ensured that the coverage for a specific day met expectations and that loss of coverage due to a data logger, battery or GPS problems would be identified and corrected. This daily review step was also used to identify skipped swaths in each data set, if any existed. In addition, EKKO_View software (Sensors and Software, Inc.) was also used to review the integrity of the 
GPR data within the .HD1 data files. After the daily checks were performed, all files were uploaded to the HGI server for processing. By the following day, the office engineer contacted the field engineer to identify any data from the previous day that required re-collection, if any existed.

Table 1. Survey Dates, Locations Surveyed, File Folder Paths of Stored Data, and Number of Lines Collected for Each Data Set in TX-TY Farm GPR Survey.

\begin{tabular}{|c|c|c|c|}
\hline Date & Collection Area & Folder Name & \# of Lines \\
\hline March 18, 2008 & $\mathrm{TX}$ & 2007-036 TxTy Farm SGE\Data\GPR\PROJECT0 & 11 \\
\hline March 19, 2008 & $\mathrm{TX}$ & 2007-036 TxTy Farm SGE\Data\GPR\PROJECT1 & 46 \\
\hline March 20, 2008 & $\mathrm{TX}$ & 2007-036 TxTy Farm SGE\DatalGPR\PROJECT2 & 35 \\
\hline March 24, 2008 & TY & 2007-036 TxTy Farm SGE\Data\GPR\PROJECT3 & 44 \\
\hline March 26, 2008 & $\alpha$-zone/TX(/TY) & 2007-036 TxTy Farm SGE\Data\GPR\PROJECT4 & 41 \\
\hline March 27, 2008 & $\mathrm{TX}$ & 2007-036 TxTy Farm SGE\Data\GPR\PROJECT5 & 41 \\
\hline March 28, 2008 & $\mathrm{TX}$ & 2007-036 TxTy Farm SGE\DatalGPR\PROJECT6 & 29 \\
\hline March 31, 2008 & $\mathrm{TX}$ & 2007-036 TxTy Farm SGE\Data\GPR\PROJECT7 & 26 \\
\hline April 1, 2008 & TY & 2007-036 TxTy Farm SGE\DatalGPR\PROJECT8 & 26 \\
\hline April 2, 2008 & TY/ $\alpha$-zone & 2007-036 TxTy Farm SGE\Data\GPR\PROJECT9 & 67 \\
\hline April 3, 2008 & $\mathrm{CA}$ & 2007-036 TxTy Farm SGE\Data \GPR\PROJECT 10 & 58 \\
\hline
\end{tabular}

\subsubsection{Processing and Plotting}

All data processing was performed using software provided by Sensors and Software, Inc., the manufacturer of the GPR equipment. EKKO_View software, Version 2, was used to view the line data with a variety of enhancement filters that allowed HGI scientists to reduce ringing (noise) within the data while drawing out GPR anomalies. IcePicker software, Version 4.0, was used to record the location and depth of GPR anomalies, called "hyperbola picks." A selection of GPR anomalies within each line was used to fit a calibration hyperbola to calculate an average wave propagation velocity through the soil medium (approximately $0.09 \mathrm{~m} /$ nanosecond or $0.3 \mathrm{ft} /$ nanosecond). This velocity was entered into the setup page of IcePicker, which used the velocity to calculate the depth of the user selected hyperbola picks.

The hyperbola picks for each line within a grid were merged into a grid-specific data file, called a "summary pick file." A two-dimensional, plan-view plot was generated from the spatial locations of the GPR anomalies within the summary pick file. Each anomaly was represented by a colored circle, where the colors represented a range of depths. For example, the shallowest GPR hyperbola picks, from 0 to 0.5 meters ( 0 to 1.6 feet) below ground surface, were represented by light pink dots. A total of six depth classes were used for plotting, and colors for the classes were chosen based on the rainbow color scale so that picks similar in depth placed in an adjacent class could be grouped together more easily. 
Ground penetrating radar is most sensitive to objects that cross the survey path at a perpendicular angle. Therefore the plotted anomalies are segregated into east-west and north-south lines. The GPR anomalies were layered over a site feature map and satellite photo provided by CH2M HILL.

The plots of GPR hyperbola picks were then reviewed and compared by HGI personnel with neighboring GPR picks of similar depth in order to distinguish continuous linear features. An example of this interpretation step is given in Figure 6. For each pipe, a GPR hyperbola pick should be located directly at the pipe location. The pipe and ideal pick location are shown in Figure 6 as a solid black line and a filled circle. However, due to imperfect GPS geo-referencing (the GPS is accurate to 0.3 meters [ 1 feet]), there is a slight offset of the GPR pick. The offset typically correlates with the direction of travel, giving the linear pipe feature a herringbone effect. An example of the offset location in the GPR pick is given by the dashed circle. The RTK GPS greatly reduced the herringbone effect by increasing the accuracy of the data point location. The pipe is interpreted as falling within the center of the picks. The interpretation of all picks forms a set of linear features, which were subsequently digitized in Surfer $^{\circledR}$ software.

The last step was to associate each pipe with a corresponding depth. A depth was assigned to a pipe by considering the depths of all picks used to interpret each pipe and using an average of those depths. The final interpretation plot will have the pipe location represented as a solid straight line.

Figure 6. Example Interpretation of GPR Hyperbola Picks.

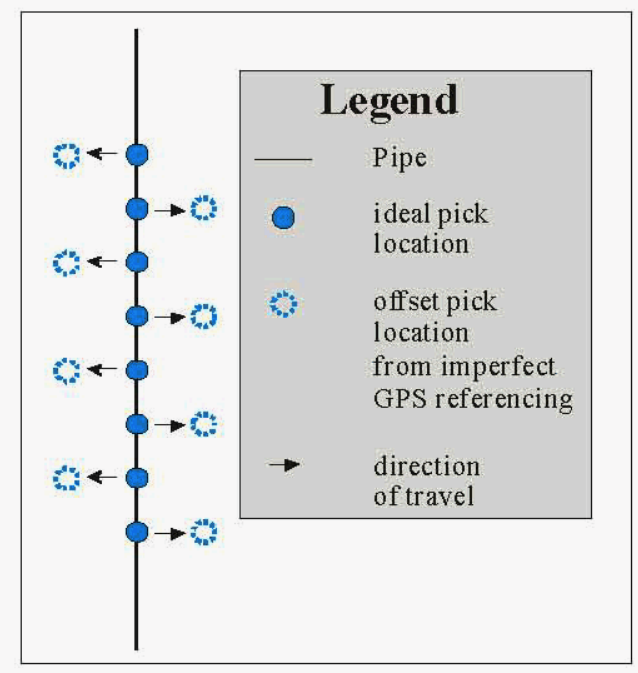




\subsection{ANALYSIS, RESULTS AND INTERPRETATION}

\subsection{EXISTING INFRASTRUCTURE}

Information on currently existing infrastructure for TX and TY farms was plotted for comparison with GPR data results. The infrastructure maps were compiled from a review of available engineering drawings. Known existing infrastructure helps to verify data quality and can provide information on the depth and size of any undocumented metallic objects detected in the survey. Figure 7 shows the infrastructure, including pipes and tanks for TX and TY tank farms. It should be noted that the infrastructure map contained in Figure 7 is likely to be partially schematic and should not be considered an "as built." Therefore differences between these maps and the GPR results are expected. 
Figure 7. TY and TY Tank Farms Infrastructure.

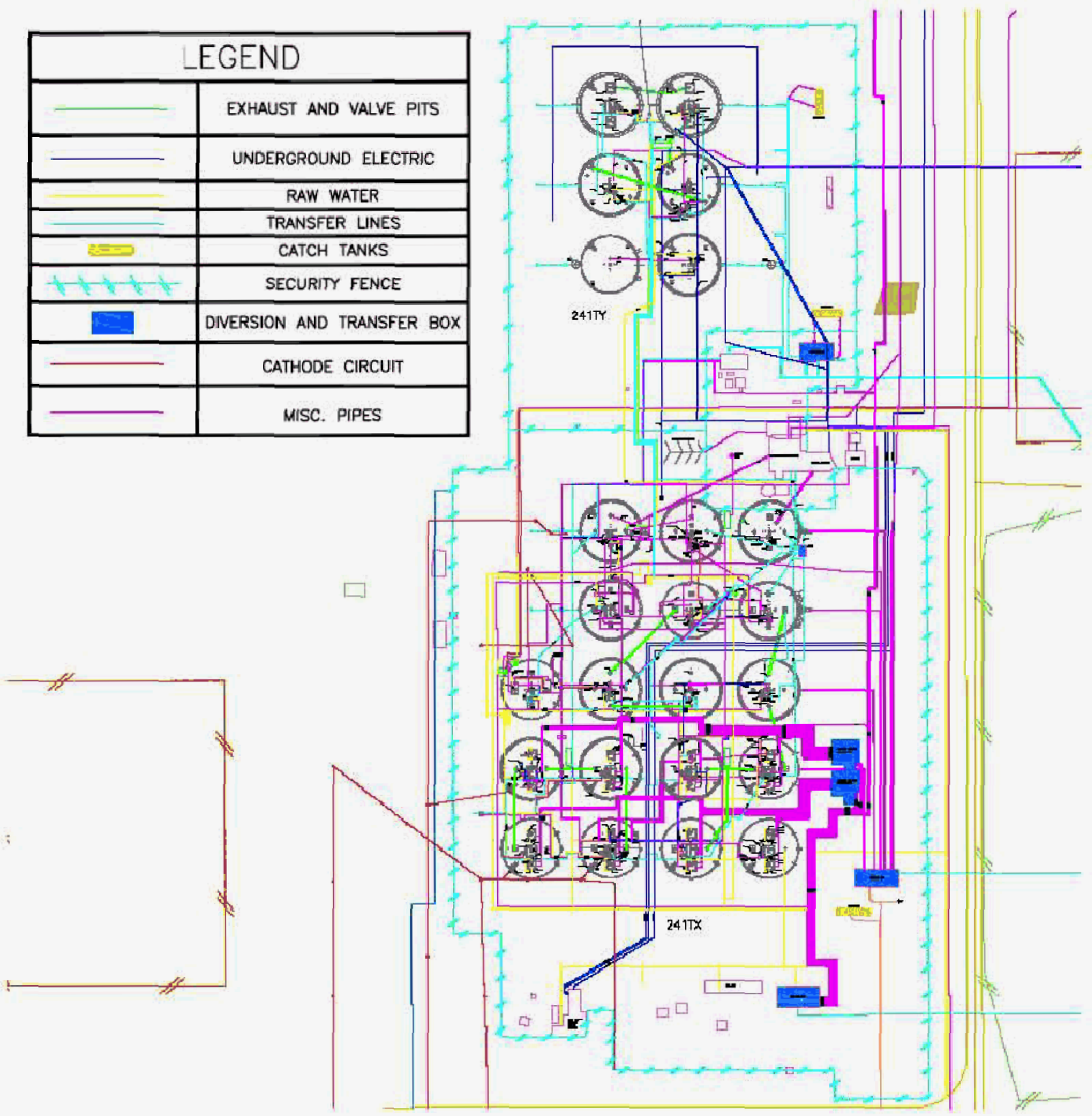




\subsection{ANOMALY PICKS}

The hyperbola anomaly picks from the TX and TY tank farms areas are shown in Figures 8 through 11. Subsurface objects produce characteristic anomalous responses that are identified in the picking software. The picks were geo-referenced and segregated by depth. The figures are also separated among those anomalies picked from GPR lines oriented in the north/south direction from anomalies picked from lines in the east/west direction. The orientation of linear features will produce different results in each survey direction, therefore both must be considered when processing the data. Depth of response is also recorded for use in data interpretation and shown in different colors. 
Figure 8. East-West Anomaly Picks in 241-TX Farm.

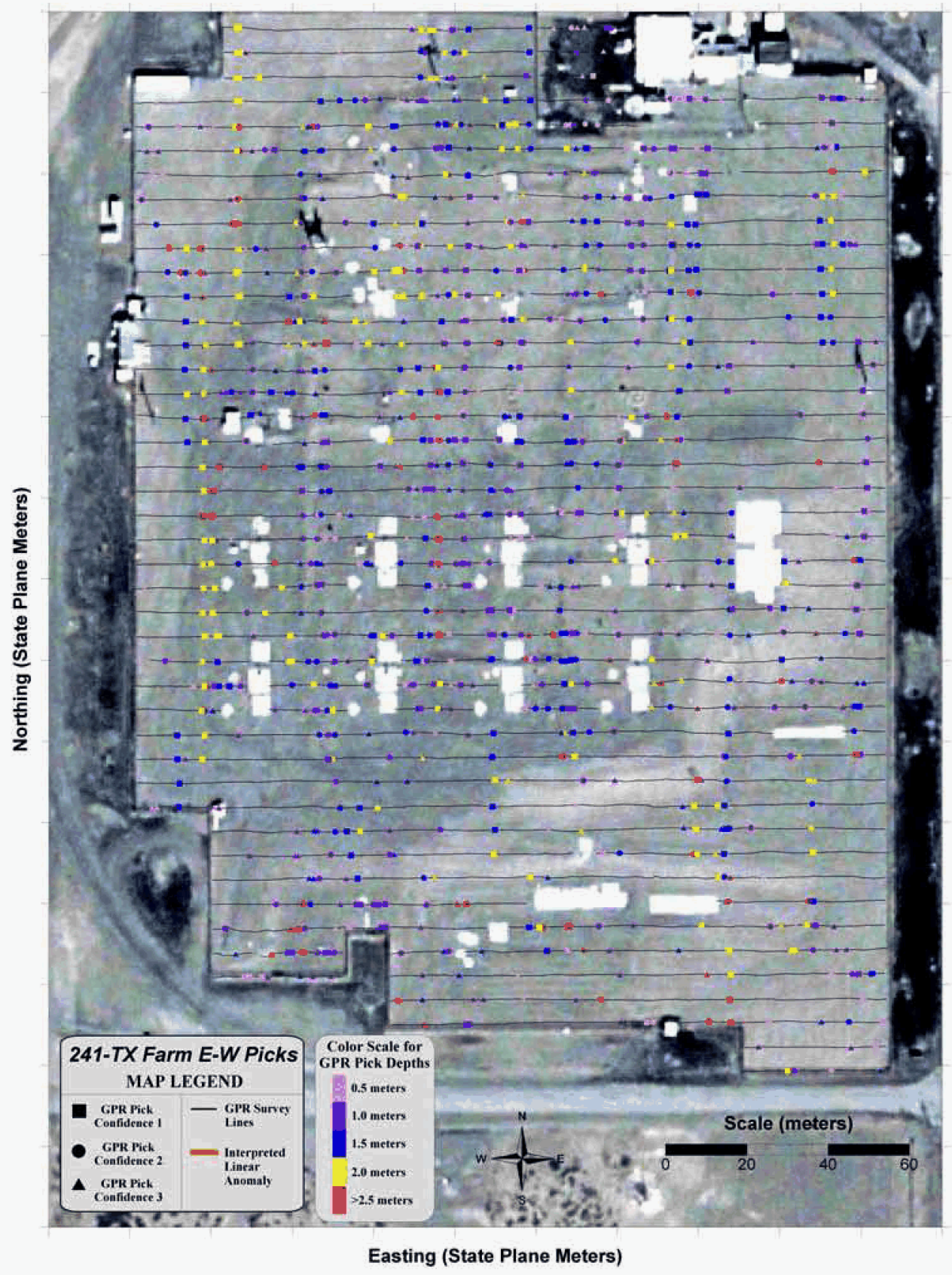


Figure 9. North-South Anomaly Picks in 241-TX Farm.

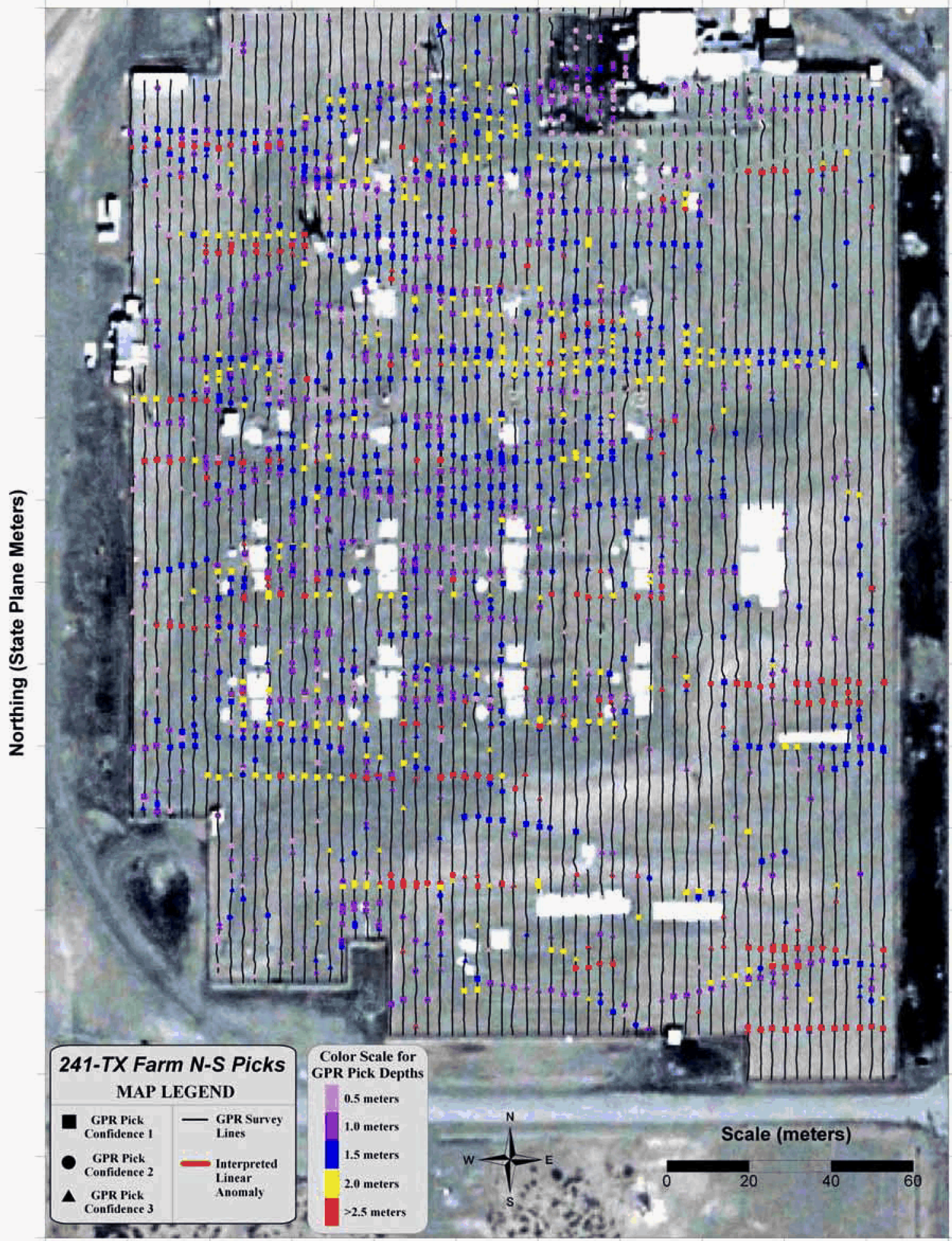

Easting (State Plane Meters) 
Figure 10. East-West Anomaly Picks in 241-TY Farm.

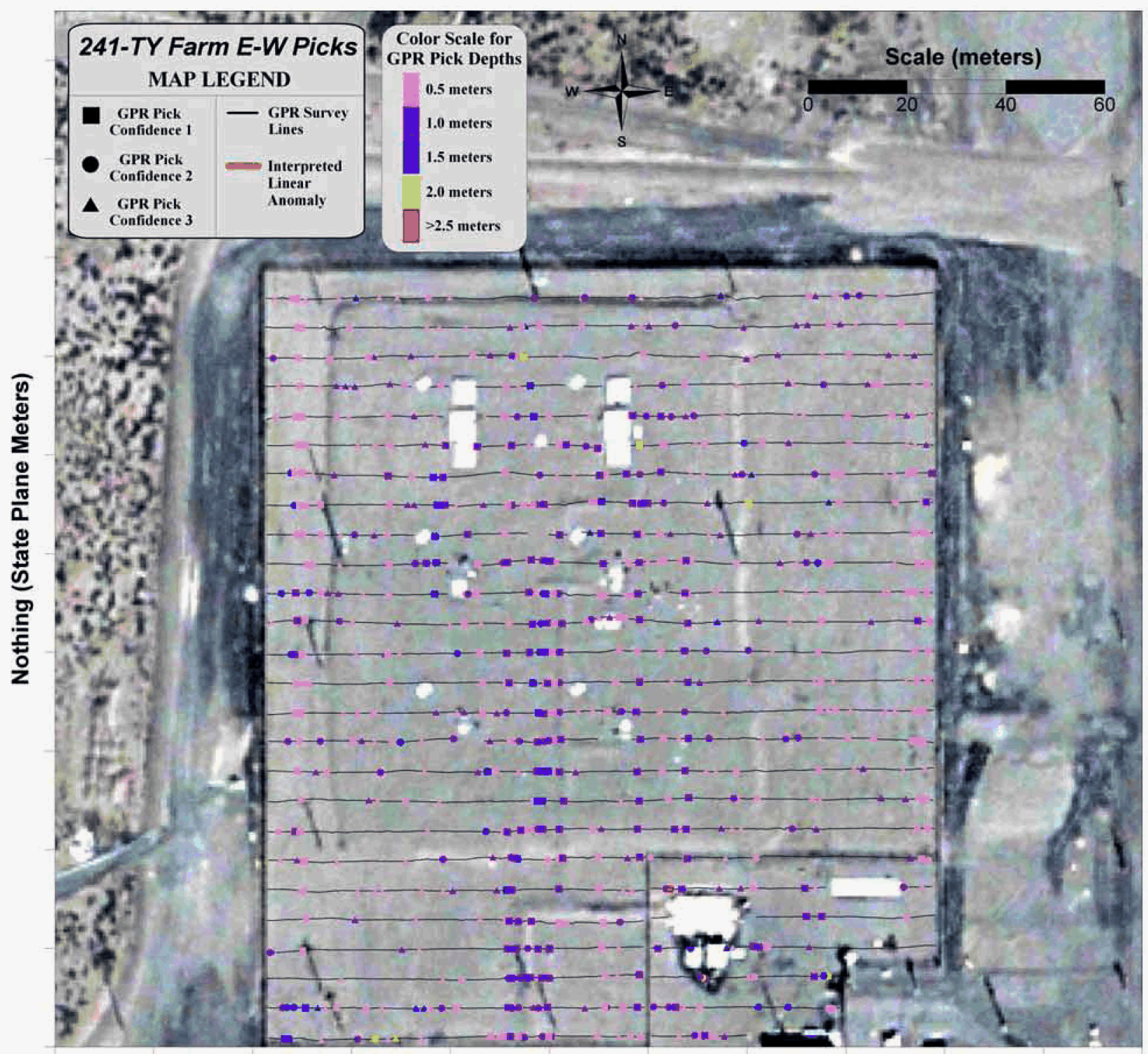

Easting (State Plane Meters) 
Figure 11. North-South Anomaly Picks in 241-TY Farm.

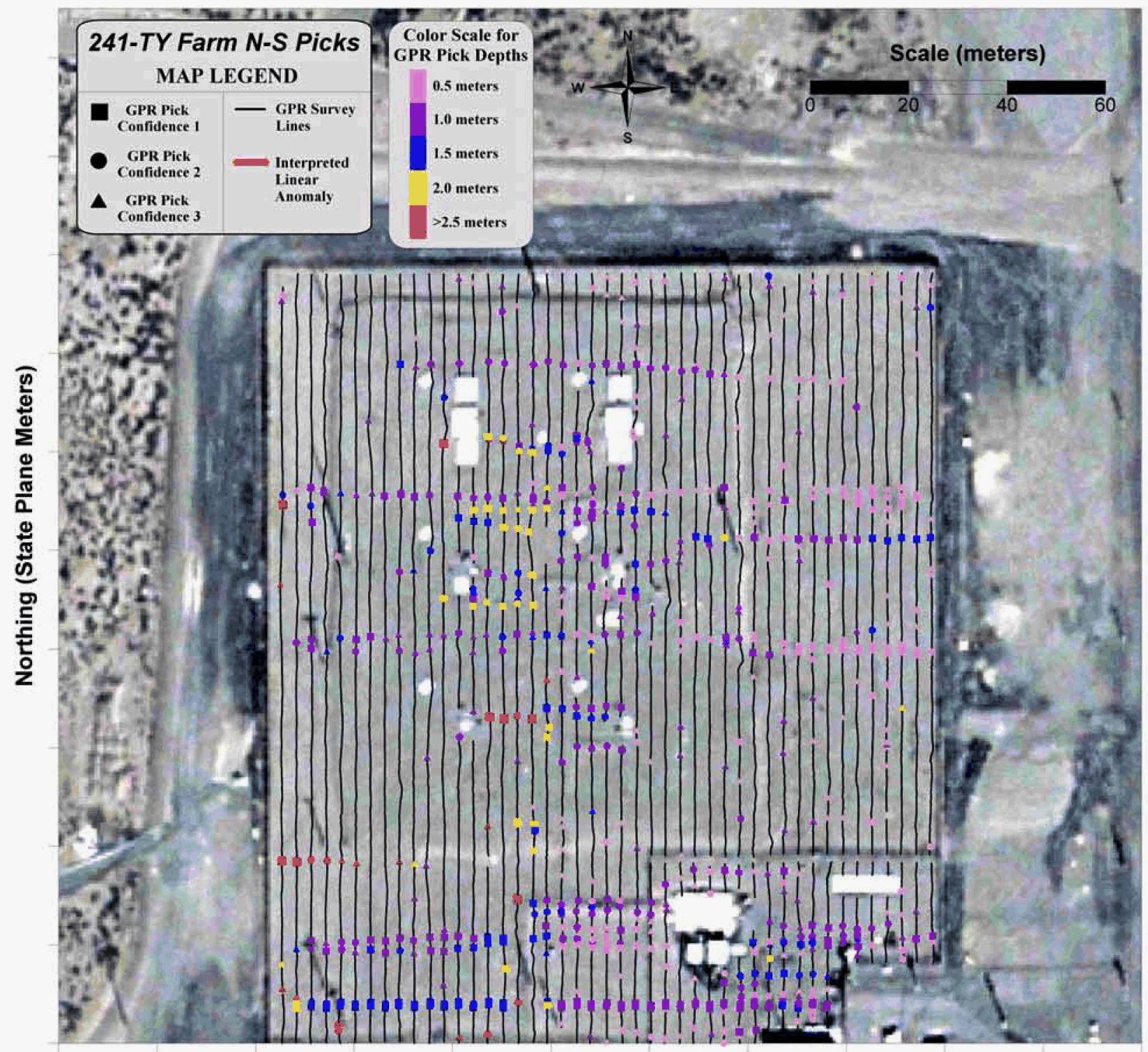

Easting (State Plane Meters)

\subsection{TNTERPRETED INFRASTRUCTURE}

Ground penetrating radar anomaly picks that occur in a linear pattern and at similar depths can be interpreted as subsurface linear features, and likely due to buried pipe infrastructure. The interpretations from GPR anomaly picks for the northem and southem areas of the TX tank farm are shown in Figures 12 and 13 and in Figures 14 and 15 for the northern and southern areas of the TY tank farm area. The lines drawn on these figures have been drawn to approximate the general inferred locations of the buried pipe infrastructure. The depth of the inferred 
infrastructure was then estimated from the depth values of the picks used in the interpretation. These depth interpretations are provided for the northern and southern areas of the TX tank farm in Figures 16 and 17 and of the TY tank farm in Figures 18 and 19.

Figure 12. Interpreted Infrastructure in 241-TX Tank Farm (North Area).

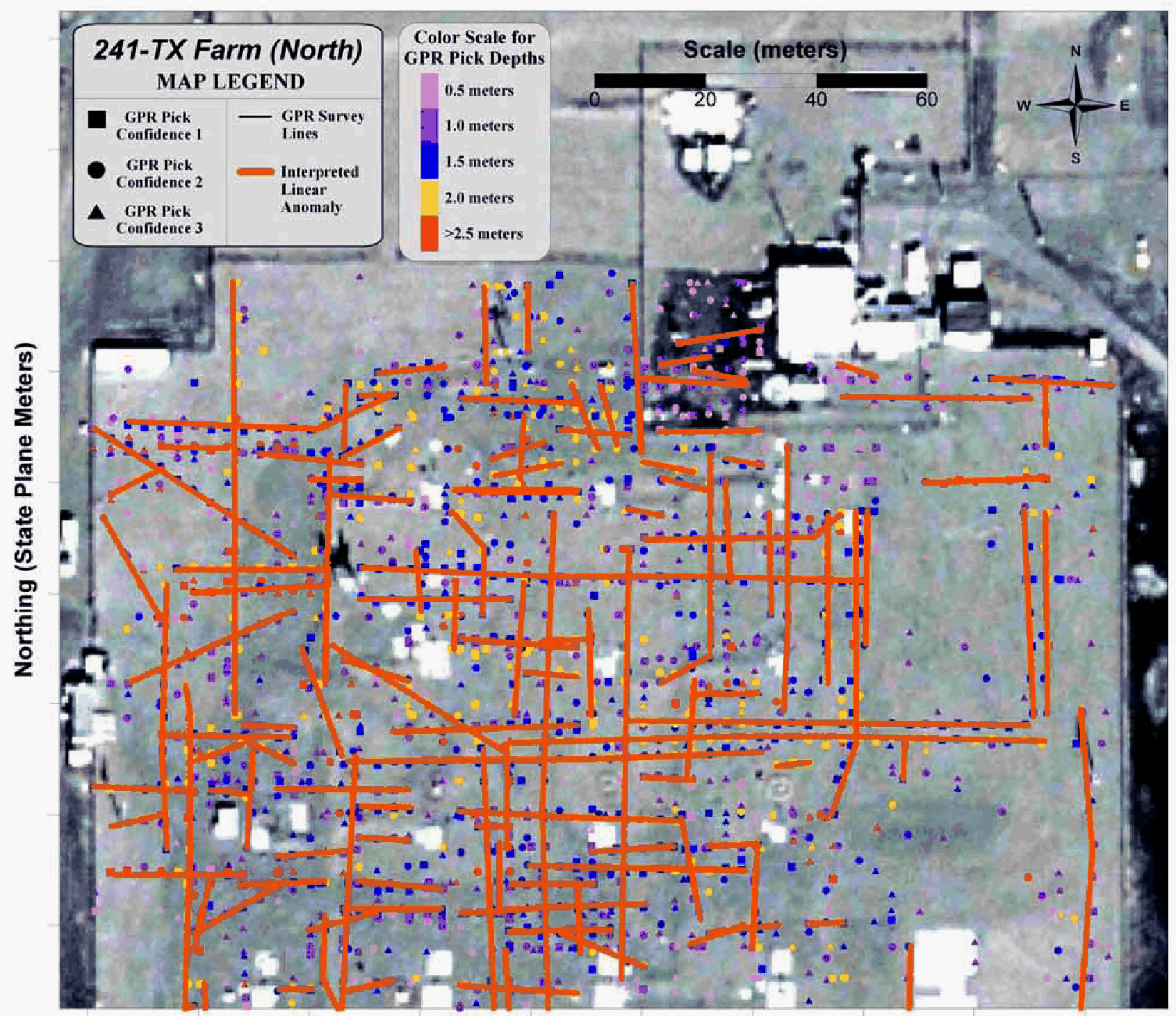

Easting (State Plane Meters)

A comparison of the interpretation of the locations and estimated depths of pipe infrastructure inferred from the GPR survey (see Figures 16 through 19) with maps of known infrastructure (see Figure 7) point out two important aspects of the survey results: The survey results generally confirm the existence of documented infrastructure, as well as identify and highlight locations of possible additional undocumented subsurface metallic objects and pipe infrastructure. 
Figure 13. Interpreted Infrastructure in 241-TX Tank Farm (South Area).

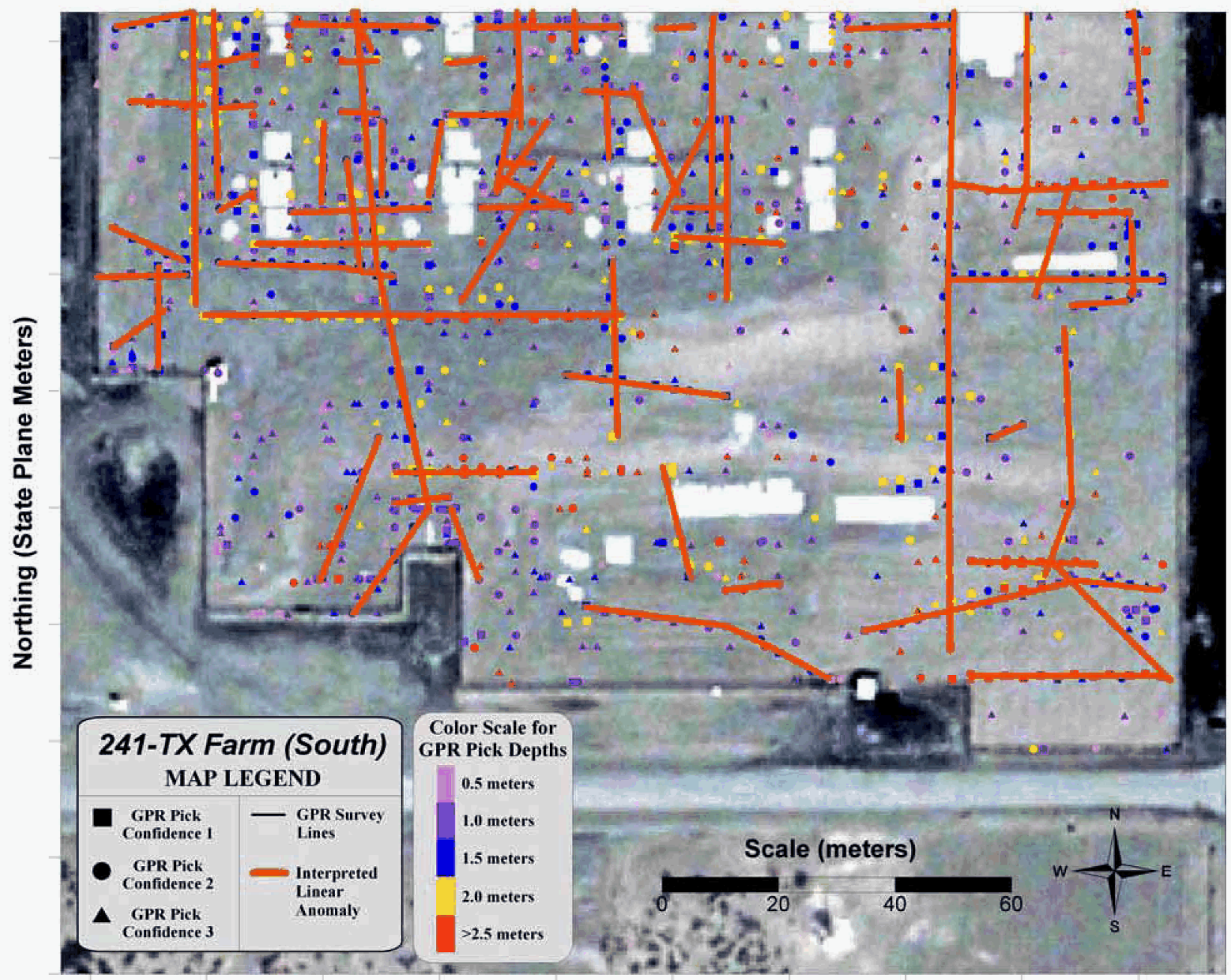

Easting (State Plane Meters) 
Figure 14. Interpreted Infrastructure in 241-TY Tank Farm (North Area).

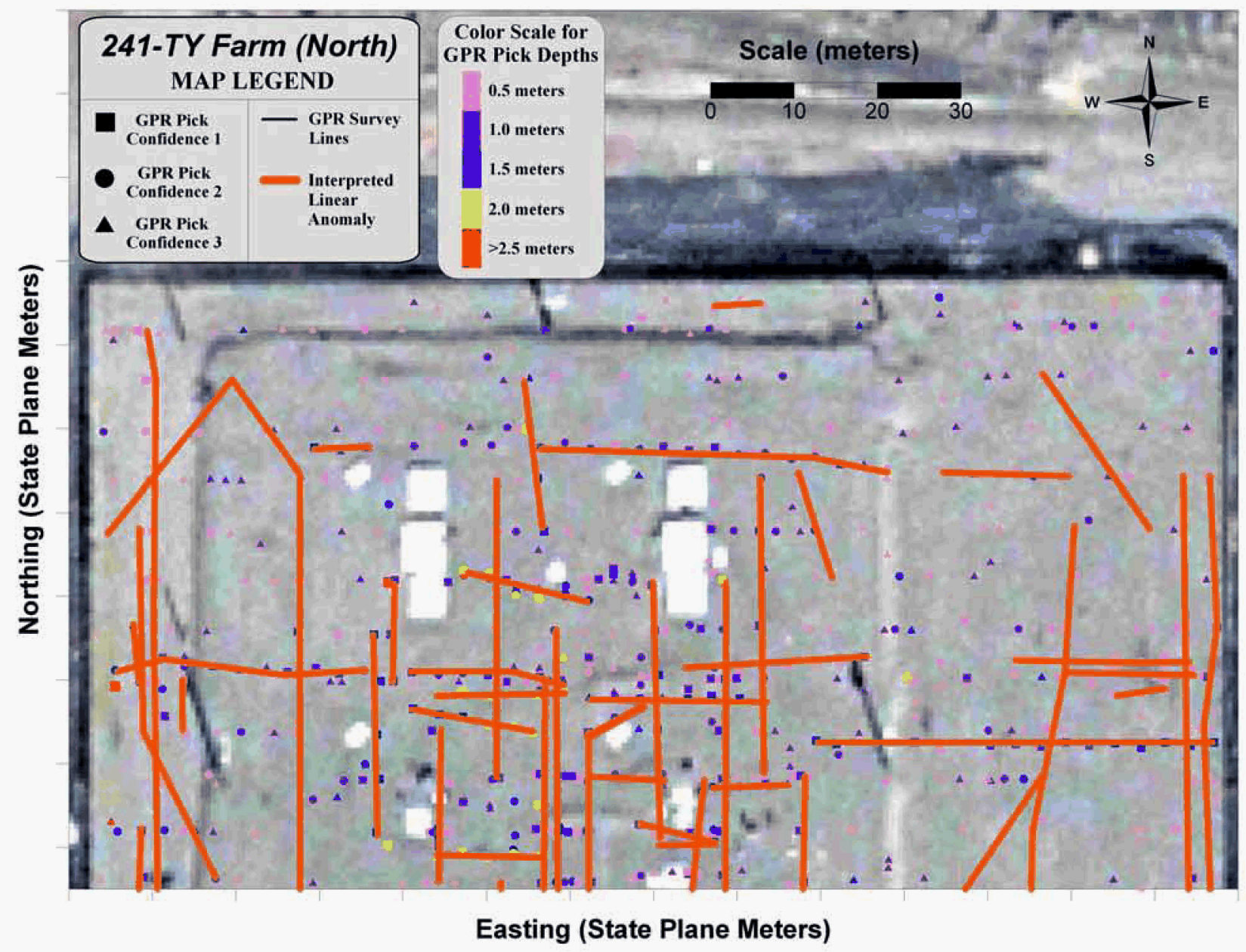


Figure 15. Interpreted Infrastructure in 241-TY Tank Farm (South Area).

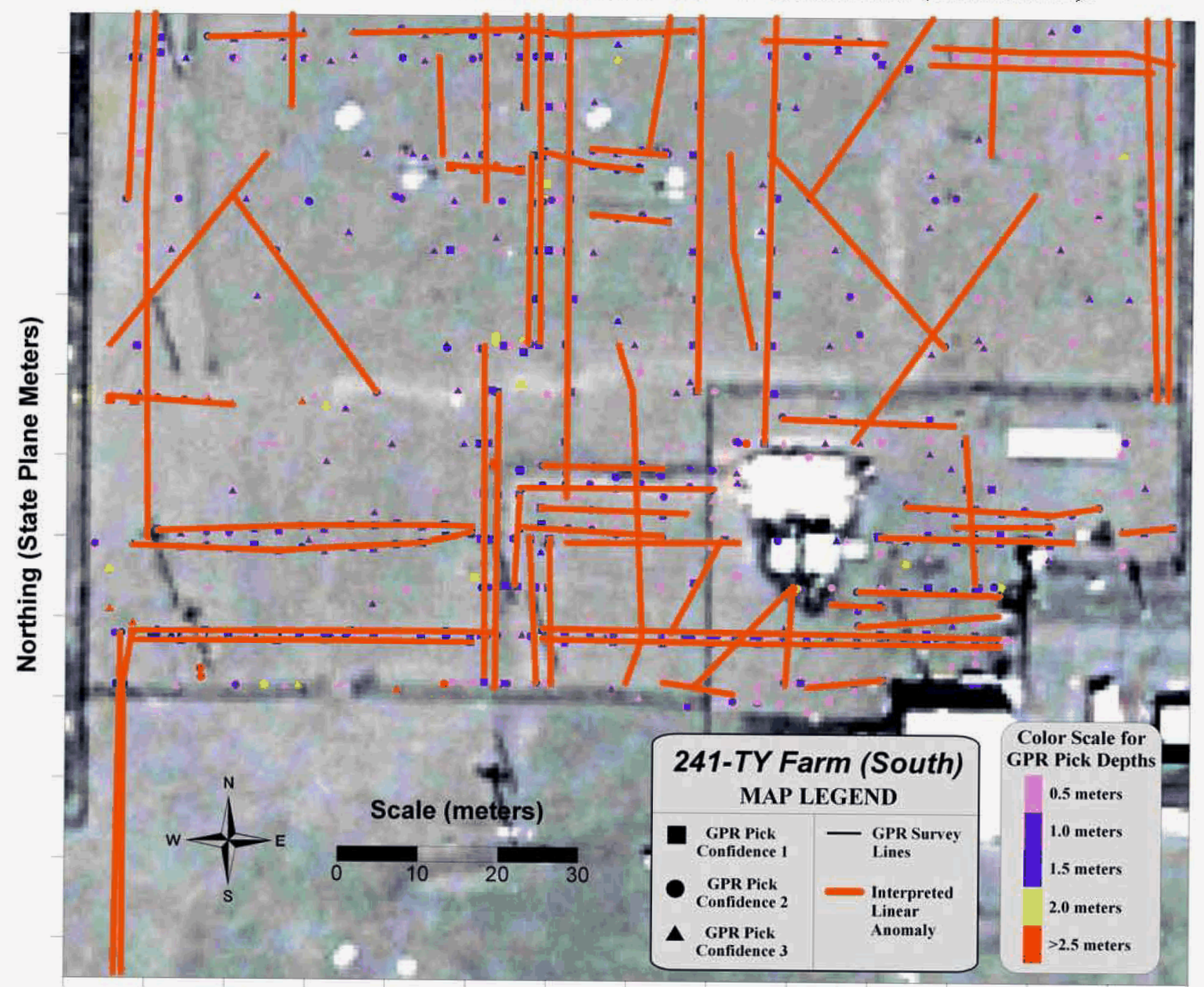

Easting (State Plane Meters) 
Figure 16. Interpreted Locations and Depths of Pipe Infrastructure in 241-TX Farm (North Area).

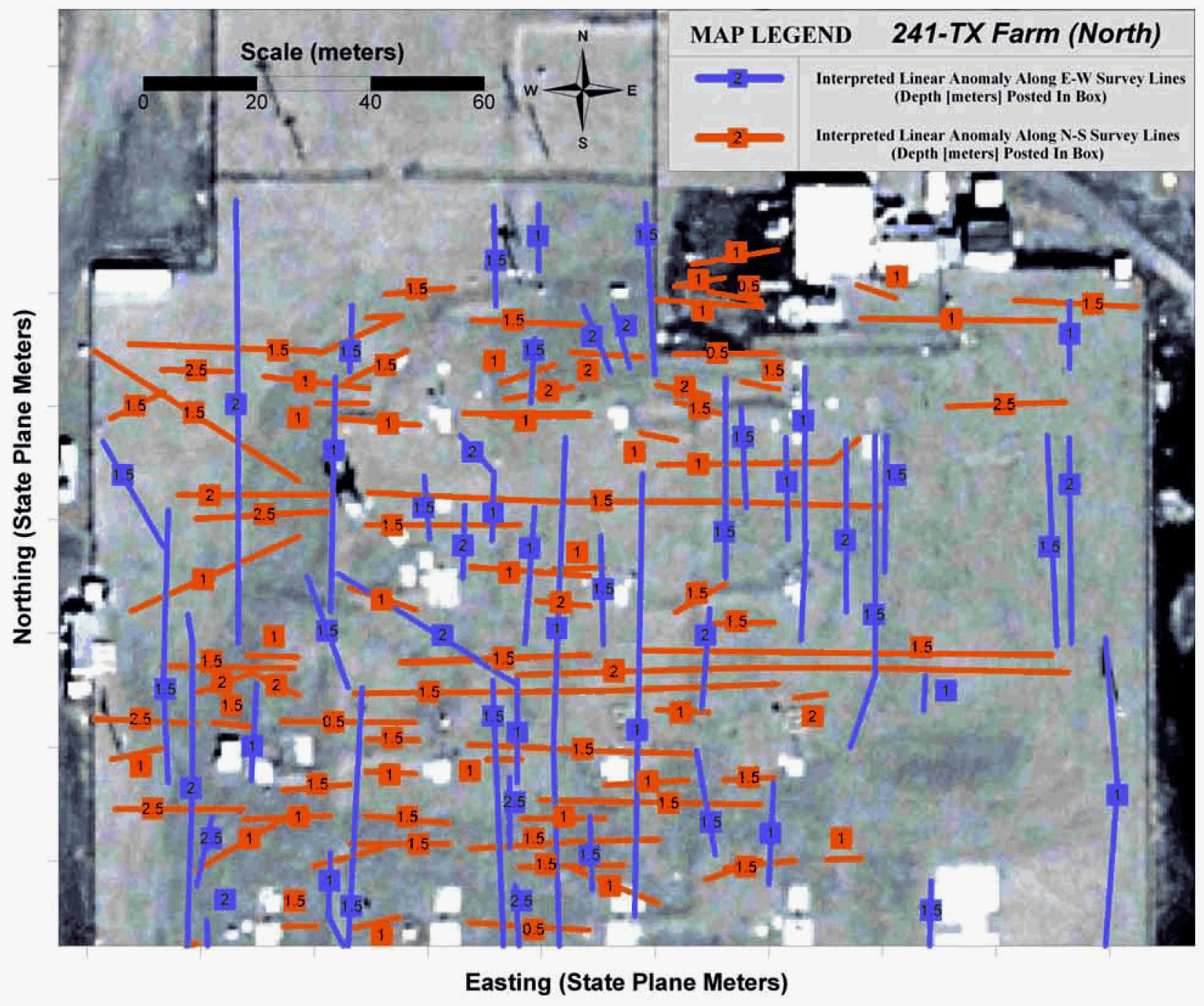


Figure 17. Interpreted Locations and Depths of Pipe Infrastructure in 241-TX Farm (South Area).

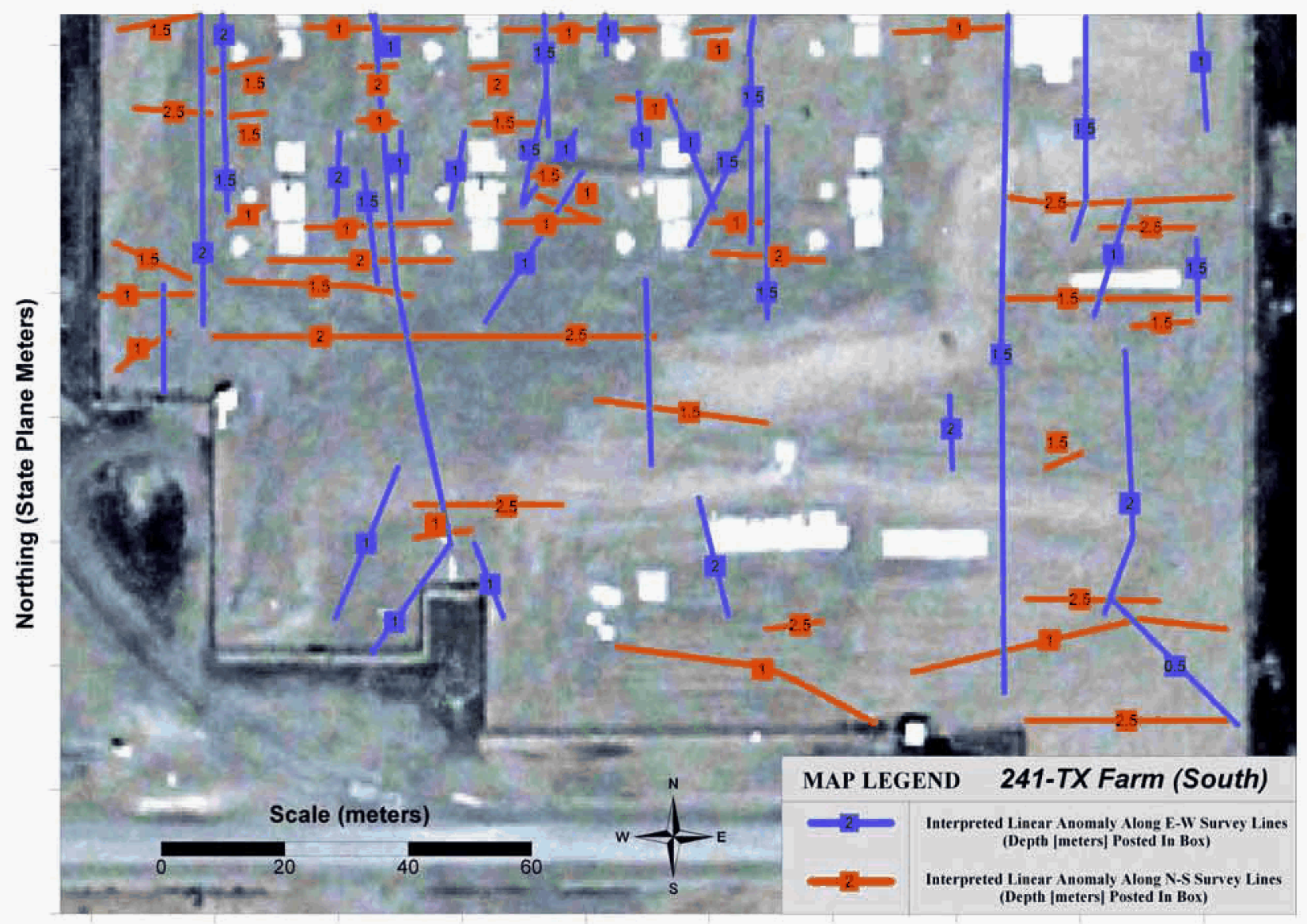

Easting (State Plane Meters) 
Figure 18. Interpreted Locations and Depths of Pipe Infrastructure in 241-TY Farm (North Area).

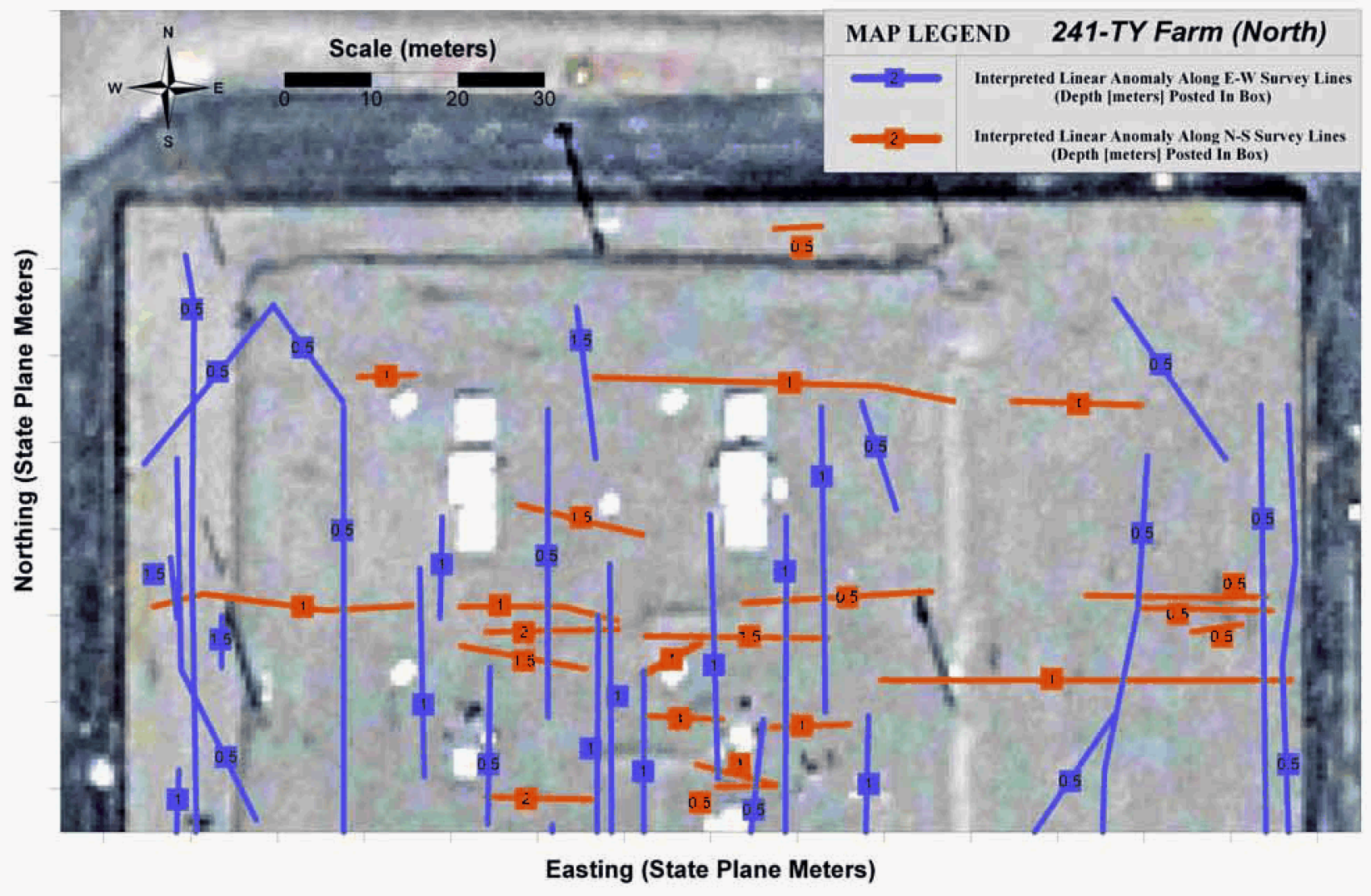


Figure 19. Interpreted Locations and Depths of Pipe Infrastructure in 241-TY Farm (South Area).

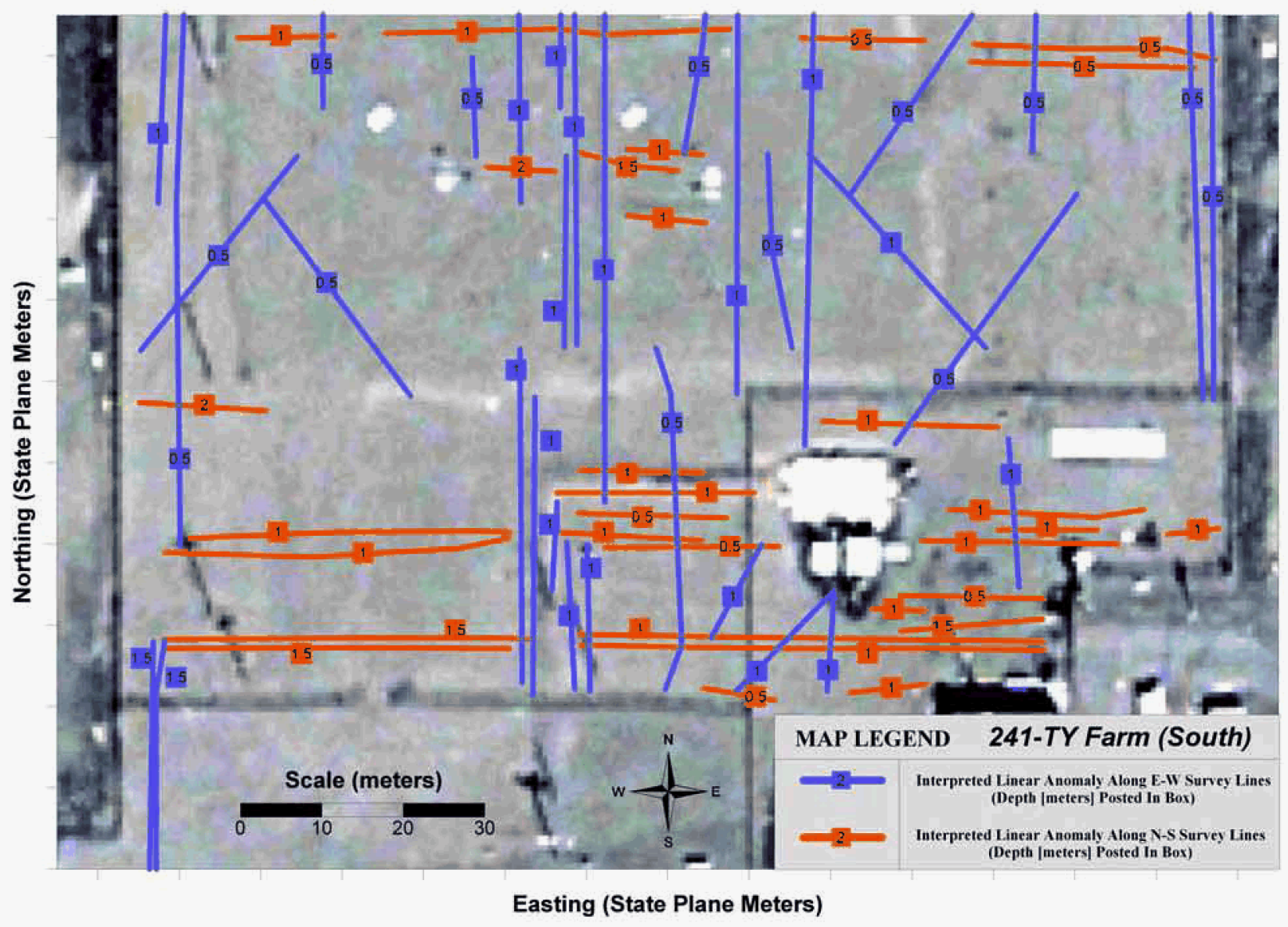




\subsection{CONCLUSIONS}

Ground penetrating radar surveys were conducted within the perimeter of TX and TY tank farms to map the location of metal objects that may interfere with high resolution resistivity ${ }^{\mathrm{TM}}$ $\left(\mathrm{HRR}^{\mathrm{TM}}\right)$ measurements. The surveys were part of the broad application of subsurface geophysical exploration that is being conducted at the TX-TY tank farm area. Data coverage included a total of included a total of 30.42 line-kilometers throughout the tank farms. Total aerial coverage of the GPR survey was approximately 15.95 acres.

Processing of the GPR data included picking the hyperbolas that result from energy diffracting from metal pipes. The diffraction hyperbolas produce a distinct signature in the data, and the depths to the hyperbolas were calculated by estimating the velocity of EM waves traveling through the tank farm soil. Each hyperbola pick was geo-referenced accurately using a GPS with differential correction.

From the GPR hyperbola picks, pipes were interpreted by considering those picks that appear to coincide with a line oriented either in the east/west or north/south directions. The final depth of the interpreted pipe was calculated from an average of the picks used to interpret the pipe. The results indicate that the TX-TY tank farm area is rich in subsurface infrastructure that could potentially interfere with HRR imaging of subsurface contaminant plumes. A comparison of the interpretation of the locations and estimated depths of pipe infrastructure inferred from the GPR survey with maps of known infrastructure point out two important aspects of the survey results: The survey results generally confirm the existence of documented infrastructure, as well as identify and highlight locations of possible additional undocumented subsurface metallic objects and pip infrastructure.

The specific details of how the GPR results were used to support the resistivity data processing will be documented in the subsequent TX-TY farm SGE resistivity report.

It is recommended that if deeper surveying is needed then a lower frequency GPR antenna be utilized. Currently, a 100 megahertz is the lowest frequency available for production surveying, which should image to approximately 6 meters ( 20 feet) below ground surface. Unfortunately, a lower frequency antenna has a diminished target resolution and will not be suitable for detecting small pipelines less than approximately 0.3 -meter (1-foot) diameter. 


\subsection{REFERENCES}

Brevick, C.H., 1995, Historical Tank Content Estimate for the Northwest Quadrant of the Hanford 200 West Area, WHC-SD-WM-ER-351, Revision 1, Westinghouse Hanford Company, Richland, Washington.

Davis, J.L., and A.P. Annan, 1989, "Ground penetrating radar for high resolution mapping of soil and rock stratigraphy," Geophysical Prospecting, 37: 531-551, A-CUBED Inc., Mississauga, Ontario, Canada.

Hanlon, 2005. Hanlon, B.M., 2005, Waste Tank Summary Report for Month Ending November 30, 2004, HNF-EP-0182, Revision 200, CH2M HILL Hanford Group, Inc., Richland, Washington.

Reidel, S.P., D.G. Horton, Y.J. Chien, D.B. Barnett, and K. Singleton, 2006, Geology, Hydrogeology, Geochemistry, and Mineralogy Data Package for the Single-Shell Tank Waste Management Areas at the Hanford Site, RPP-23748, Revision 0, CH2M HILL Hanford Group, Inc., Richland, Washington.

RPP-PLAN-35244, 2007, Work Plan for Surface Geophysical Exploration of the TX and TY Tank Farm and Surrounding Area, Revision 0, CH2M HILL Hanford Group, Inc., Richland, Washington.

RPP-RPT-36893, 2008, Surface Geophysical Exploration of TX and TY Tank Farms at the Hanford Site: Results of Background Characterization with Magnetics and Electromagnetics, Revision 0, CH2M HILL Hanford Group Inc., Richland, Washington. 